\title{
Global carbon budget of reservoirs is overturned by the quantification of drawdown areas
}

\author{
Philipp S. Keller $\mathbb{1}^{1 凶}$, Rafael Marcé ${ }^{2,3}{ }^{2,3}$, Biel Obrador ${ }^{\left(\mathbb{B}{ }^{4}\right.}$ and Matthias Koschorreck (iD)
}

Reservoir drawdown areas-where sediment is exposed to the atmosphere due to water-level fluctuations-are hotspots for carbon dioxide $\left(\mathrm{CO}_{2}\right)$ emissions. However, the global extent of drawdown areas is unknown, precluding an accurate assessment of the carbon budget of reservoirs. Here we show, on the basis of satellite observations of 6,794 reservoirs between 1985 and 2015, that $15 \%$ of the global reservoir area was dry. Exposure of drawdown areas was most pronounced in reservoirs close to the tropics and shows a complex dependence on climatic (precipitation, temperature) and anthropogenic (water use) drivers. We re-assessed the global carbon emissions from reservoirs by apportioning $\mathrm{CO}_{2}$ and methane emissions to water surfaces and drawdown areas using published areal emission rates. The new estimate assigns 26.2 (15-40) (95\% confidence interval) $\mathrm{TgCO}_{2}-\mathrm{C} \mathrm{yr}^{-1}$ to drawdown areas, and increases current global $\mathrm{CO}_{2}$ emissions from reservoirs by $53 \%$ (60.3 (43.2-79.5) $\left.\mathrm{TgCO}_{2}-\mathrm{C} \mathrm{yr}^{-1}\right)$. Taking into account drawdown areas, the ratio between carbon emissions and carbon burial in sediments is 2.02 (1.04-4.26). This suggests that reservoirs emit more carbon than they bury, challenging the current understanding that reservoirs are net carbon sinks. Thus, consideration of drawdown areas overturns our conception of the role of reservoirs in the carbon cycle.

$\mathrm{R}$ eservoirs, like inland aquatic ecosystems in general, are recognized as a globally relevant source of greenhouse gases $(\mathrm{GHGs})^{1}$. The quantification of this GHG source has been subject to intensive research for at least two decades, and current assessments estimate reservoirs to annually emit $800 \mathrm{Tg}$ carbon dioxide equivalent $\left(\mathrm{CO}_{2} \mathrm{e}\right)$ to the atmosphere ${ }^{1}$. The exact quantification of this source is also important because GHG emissions from reservoirs may affect the carbon (C) footprint of irrigation ${ }^{2}$ and hydropower production and thus its perception as $\mathrm{C}$-neutral energy $^{3-5}$. At the same time, reservoirs act as a sediment trap, accumulating organic material from the catchment and in-lake primary production, and they have previously been shown to bury $\mathrm{C}$ at higher rates than natural lakes ${ }^{6}$. Globally, rates of organic carbon (OC) burial in reservoirs have been estimated to exceed rates of $\mathrm{C}$ emissions from reservoirs ${ }^{1,6}$.

Water-level changes are a typical feature of reservoirs and a major discriminator to natural lakes?. They are driven both by natural hydrological dynamics and water management. Water-level fluctuations have several consequences for reservoir limnology and biogeochemical cycling ${ }^{8,9}$. The most obvious consequence of water-level changes, however, is a changing water surface area (Fig. 1a). Varying portions of reservoirs are temporarily falling dry, forming the so-called drawdown area (Fig. 1b). This has two consequences for upscaling $C$ fluxes from reservoirs: (1) the variable surface area has to be considered in upscaling fluxes based on water surface, and (2) the GHG emissions from the drawdown area have to be included in reservoir $\mathrm{C}$ budgets. Although the relevance of these two points has already been acknowledged ${ }^{1}$, they have not been considered in reservoir $\mathrm{C}$ budgets ${ }^{10}$ and global upscalings $\mathrm{s}^{1,6}$ so far.

It has been shown that dry aquatic sediments in general, and drawdown areas of reservoirs in particular, emit large quantities of $\mathrm{GHGs}^{11,12}$. GHG emissions from drawdown areas are typically dominated by $\mathrm{CO}_{2}$ while $\mathrm{CH}_{4}$ is of minor importance ${ }^{13}$. Initial studies reported that the drawdown area has the potential to dominate annual $\mathrm{CO}_{2}$ emissions from reservoirs ${ }^{12,14-16}$ due to areal $\mathrm{CO}_{2}$ emissions, which are significantly higher than those from the water surface ${ }^{11} \cdot \mathrm{CO}_{2}$ emissions from dry inland waters were shown to be controlled mainly by temperature, moisture and organic-matter content of the desiccated sediments ${ }^{11}$. Extreme water-level drawdown can furthermore create hot moments of GHG emissions and may even offset $C$ burial in the sediments ${ }^{16,17}$.

To include emissions from drawdown areas into $\mathrm{C}$ budgets of reservoirs and, ultimately, into global $\mathrm{C}$ inventories, information about the spatial extent and distribution of drawdown areas is crucial. Recently, a new algorithm was developed providing 30 -year-long time series of surface-area variations in thousands of reservoirs worldwide ${ }^{18}$. In this study, we use that dataset to estimate the extent of reservoir drawdown areas globally and to identify drivers influencing the extent of drawdown areas as well as their spatial and temporal patterns. Subsequently, we re-assess global estimates of reservoirs' $\mathrm{C}$ budget (defined as emission-to-burial ratios) by partitioning total emissions into fluxes from the water surface and from the drawdown area, and propagating the uncertainty from the area, and emission and burial rates estimates. The final aim of our study is to reduce the upscaling uncertainty of $\mathrm{C}$ fluxes from reservoirs, such as GHG emissions to the atmosphere and OC burial in sediments, relying on accurate estimates of inundated and drawdown areas in reservoirs.

\section{Characterization of global reservoir drawdown}

To examine global patterns of reservoir drawdown, we quantified the spatial extent of the monthly drawdown area of each reservoir during the period 1985-2015 (total reservoir-month $n=2,429,640$ ). We subtracted the inundated surface area from the area covered by water at maximum filling level. Reservoirs were completely filled

'Department of Lake Research, Helmholtz Centre for Environmental Research - UFZ, Magdeburg, Germany. ${ }^{2}$ Catalan Institute for Water Research (ICRA), Girona, Spain. ${ }^{3}$ Universitat de Girona, Girona, Spain. ${ }^{4}$ Department of Evolutionary Biology, Ecology and Environmental Sciences, Institut de Recerca de la Biodiversitat (IRBio), University of Barcelona, Barcelona, Spain.凶e-mail: philipp.keller@ufz.de 
a

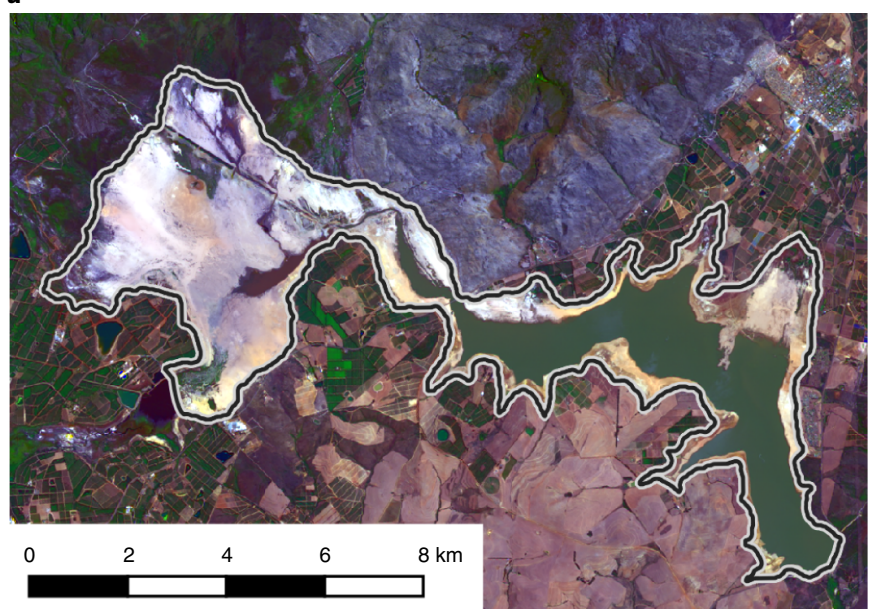

b

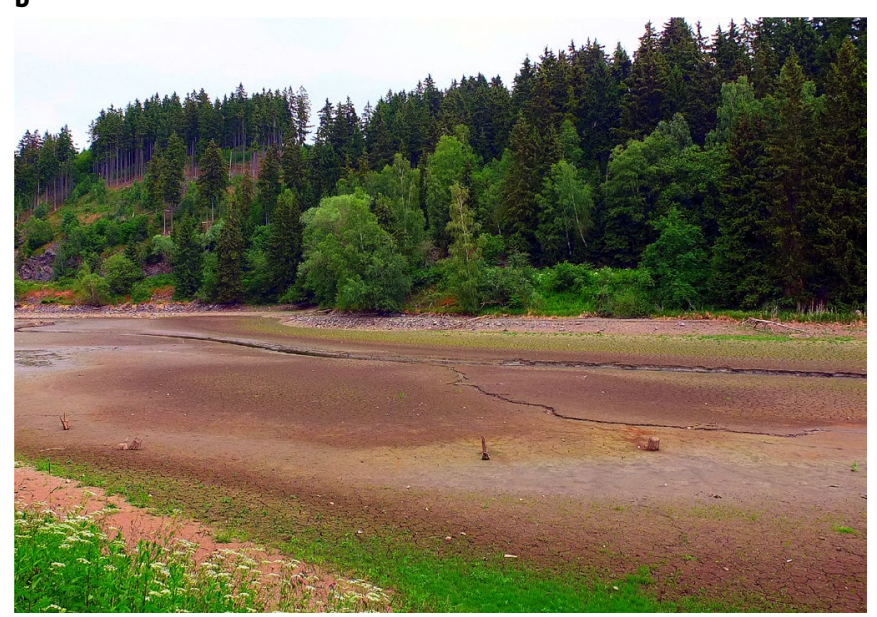

c

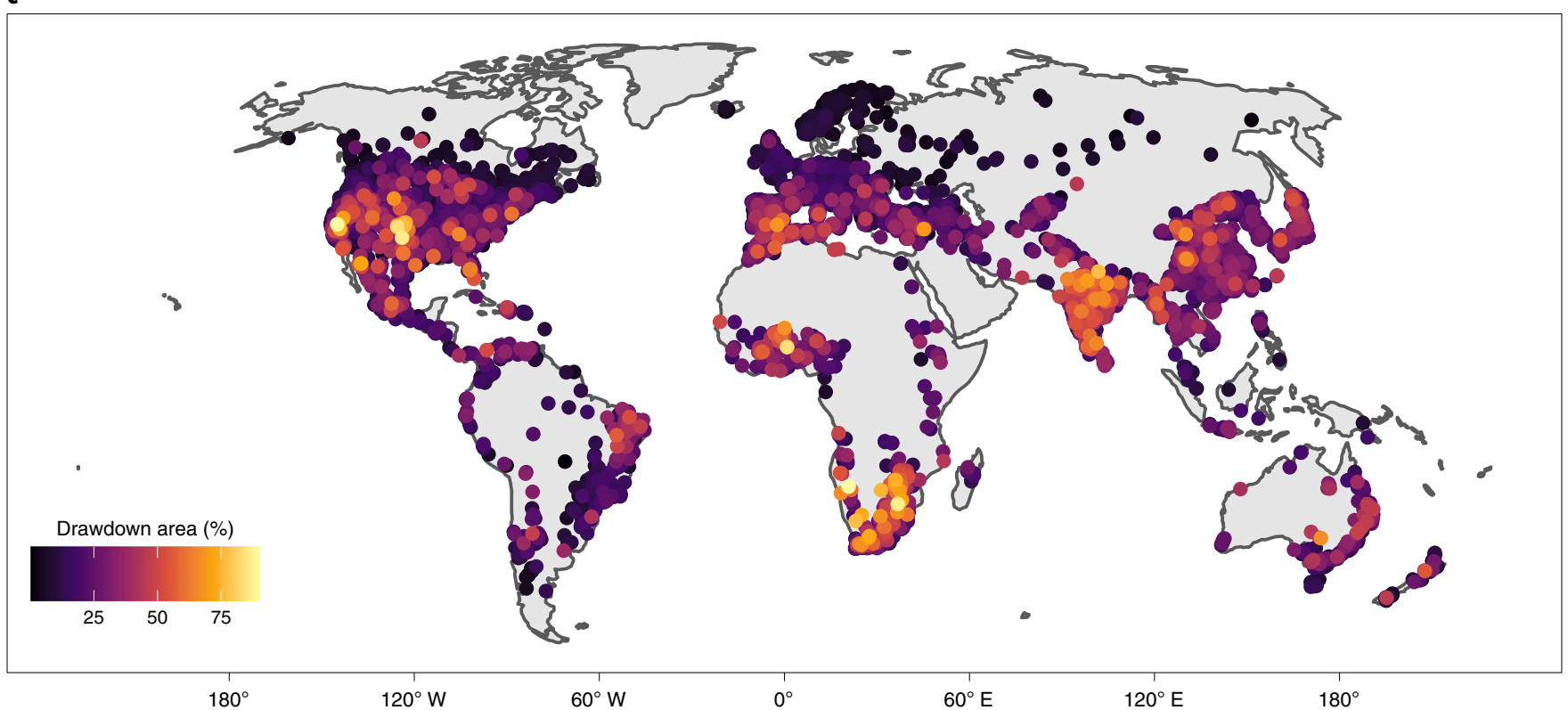

Fig. 1 The world's reservoir drawdown areas. a, Theewaterskloof Dam, South Africa, during the water crisis of 2018 . The black/white line shows the reservoir margin at maximum capacity ${ }^{31}$. Drawdown area $=73 \%$ of maximum reservoir area. b, Dry part of Hassel pre-dam, Germany, 2014 . c, Global distribution of 6,749 reservoir drawdown areas. Colours indicate average drawdown area during the period 1985-2015 as percentage of maximum reservoir area. Landsat-8 image in a courtesy of USGS; photograph in $\mathbf{b}$ courtesy of Kurt Friese.

during only $22 \%$ of the analysed period (543,353 reservoir-months had drawdown area smaller than 5\% of individual maximum reservoir area), implying that most of the time a sizeable portion of the area of reservoirs was dry. On a monthly basis, the drawdown areas covered between 9\% (January 2011) and 15\% (May 2003) of the total reservoir area ( $n=6,749$ reservoirs). On average, considering the complete period 1985-2015, 12\% (only Global Reservoir Surface Area Dataset $(\mathrm{GRSAD})^{19}, 15 \%$ when applying Pareto modelling for reservoirs $<10 \mathrm{~km}^{2}$ ) of the global reservoir area has been dry. The drawdown area depended significantly on reservoir size, with smaller reservoirs having larger (relative to reservoir size) drawdown areas (Extended Data Fig. 1). Reservoirs between $100 \mathrm{~km}^{2}$ and $1,000 \mathrm{~km}^{2}$ contributed most to the total drawdown area $\left(12,349 \mathrm{~km}^{2}, 28 \%\right.$ of total drawdown area, $n=349$; Extended Data Fig. 2).

Drawdown-area extent was not evenly distributed across the globe (Fig. 1), and the mean annual drawdown area of reservoirs was related to latitude (Fig. 2a). Small relative drawdown areas were typical in the boreal zone whereas drawdown-area extent was largest close to the tropics, where the climatic regime is characterized by a pronounced seasonality (Fig. 2b). Smaller drawdown areas were also typical towards the Equator, where diurnal variations in climate patterns generally exceed seasonal variations. The drawdown area depended also on reservoir type (Extended Data Fig. 3). Large drawdown areas were typical for reservoirs used for irrigation $($ median $=23 \%)$ and flood control (median $=15 \%)$. Small drawdown areas were particularly typical for hydropower reservoirs (median $=9 \%)$. The latitudinal pattern of reservoir drawdown inversely related to the latitudinal share of the fraction of reservoirs devoted to hydropower (Fig. 2c). Because hydropower reservoirs tended to have smaller drawdown areas, the larger share of hydropower reservoirs at higher latitudes also contributed to the smaller drawdown areas at high latitudes. We used stepwise multiple linear regression (MLR) to identify the influence of environmental and anthropogenic factors on drawdown-area extent (Methods). Models containing climatic variables (precipitation seasonality, 

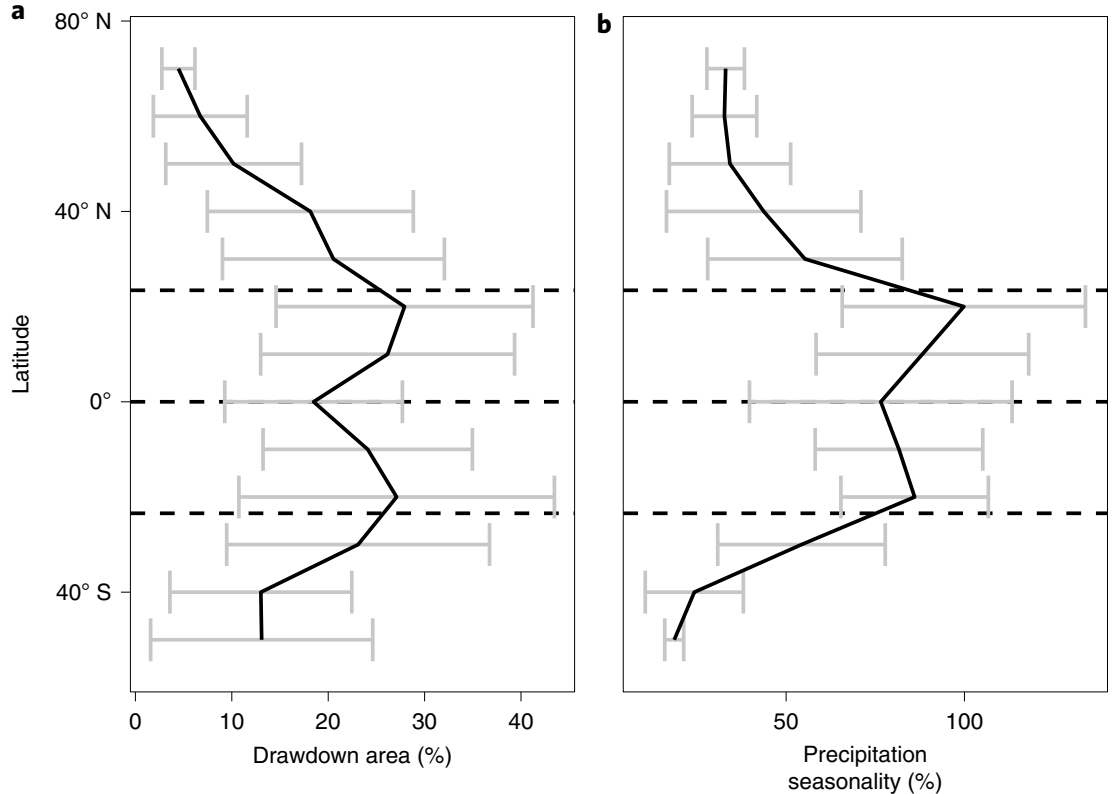

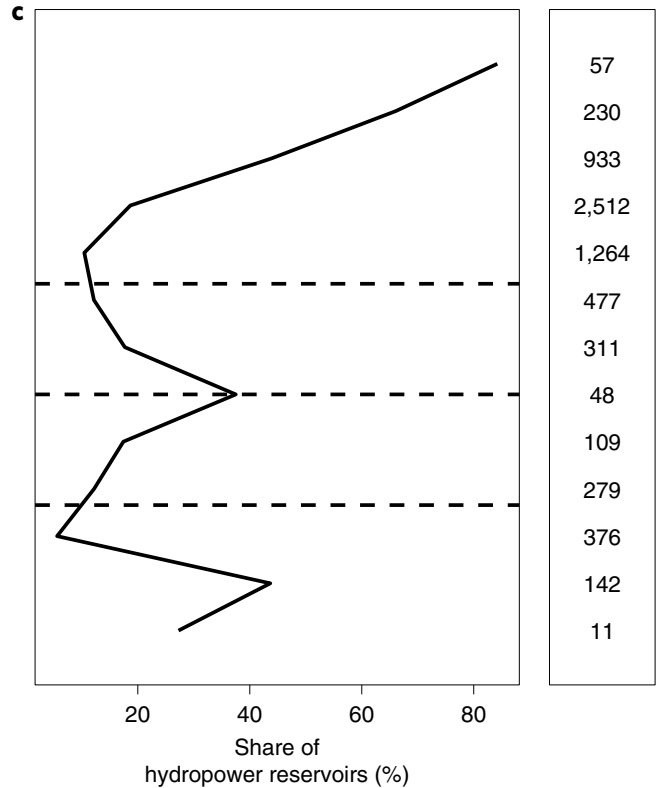

Fig. 2 | Latitudinal distribution of drawdown area and influential parameters. a, Average drawdown area of reservoirs. b, Precipitation seasonality. c, Share of hydropower reservoirs to total number of reservoirs. Data were binned into $10^{\circ}$ latitude intervals. Data are means \pm s.d. (a,b). Dashed lines indicate the northern tropic, Equator and southern tropic. Numbers in the box on the right indicate the total number of reservoirs per latitudinal bin.

mean annual temperature, water stress) and variables representing anthropogenic factors (maximum area, main use) explained $27 \%$ and $25 \%$ of the variability, respectively. Thus, the global distribution of reservoir drawdown areas was affected by both climatic and anthropogenic drivers (global MLR model, $r^{2}=0.41, P<0.001$, $n=6,749$; Supplementary Table 1 and Extended Data Fig. 4), confirming recent findings based on a one-year dataset of global reservoir levels ${ }^{20}$.

The global monthly average drawdown area did not show a significant temporal trend during the analysed period (Extended Data Fig. 5). However, increases of drawdown area were significant in $21 \%$ of all reservoirs ( $P<0.05$ for 1,404 of 6,749 reservoirs). A similar proportion of reservoirs had significantly decreasing drawdown areas ( $26 \%, P<0.05$ for 1,760 of 6,749 reservoirs). However, these findings should be handled with care because the launch of Landsat 7 in 1999 affected the temporal homogeneity of the dataset (more-frequent observations); thus, trends from individual reservoirs can be altered. Depending on latitude, total drawdown area showed a pronounced seasonality (Extended Data Fig. 5), with annual maxima occurring in fall for reservoirs located between $40^{\circ} \mathrm{N}$ and $90^{\circ} \mathrm{N}$ and either summer or spring for reservoirs located between $10^{\circ} \mathrm{N}$ and $40^{\circ} \mathrm{N}$ and between $10^{\circ} \mathrm{S}$ and $60^{\circ} \mathrm{S}$.

Extreme drawdown (drawdown areas exceeding a given threshold in respect to maximum reservoir extent) was observed in $2,666 \pm 791$ reservoirs built before 1985 (40\% of total reservoirs). Younger reservoirs (791 reservoirs, $12 \%$ of the dataset) were excluded here to prevent effects of reservoir filling. This estimate is based on averaging over a range of thresholds ( $40 \%$ to $70 \%$ of maximum reservoir area; Methods and Extended Data Fig. 6) because there is no universal definition of 'extreme drawdown' as what is 'extreme' depends on local conditions. Cape Town, South Africa, for example, prepared for 'Day Zero' in 2018, when the drawdown area of Theewaterskloof Dam was close to $70 \%$ of its maximum area (Fig. 1a) ${ }^{21}$.

\section{Implications for $\mathbf{C}$ cycling in reservoirs}

Emerging drawdown areas are inevitably coupled to shrinking water surfaces of reservoirs. Thus, all global estimates of $\mathrm{C}$ cycling in reservoirs that are based on their global surface area are directly affected by reservoir drawdown. Currently, global GHG emissions from reservoirs are estimated to be about $800(500-1,200)$

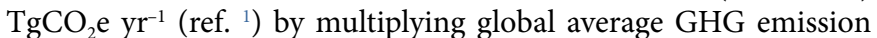
rates times the global reservoir area. However, this number is based on aquatic GHG emissions only, assuming that all reservoirs are completely filled $^{1,10}$, whereas dry aquatic sediments can emit large quantities of $\mathrm{CO}_{2}{ }^{11,12}$. We re-assessed the most recent estimate of $\mathrm{C}$ emissions from reservoirs ${ }^{1}$ by multiplying reported $\mathrm{C}$ emission rates from wet and dry reservoir areas times inundated or dry areas calculated here. We also estimated the uncertainty of our calculations by propagating the uncertainty from areas and emission rates estimates using Taylor series expansion and Monte Carlo methods (Methods and Supplementary Discussion). Multiplication of the mean $\mathrm{CO}_{2}$ flux from dry sediments (mean $=611 \mathrm{gC} \mathrm{m}^{-2} \mathrm{yr}^{-1}$, range $=9-2,301 \mathrm{gC} \mathrm{m}^{-2} \mathrm{yr}^{-1}, n=47$; Extended Data Fig. 7 and Supplementary Table 2) times the total extent of drawdown areas $(43,539(26,939-60,130)) \mathrm{km}^{2} ;$ Methods and Supplementary Discussion) results in a total $\mathrm{CO}_{2}$ carbon flux of 26.2 (15-40) $\mathrm{TgCO}_{2}-\mathrm{C} \mathrm{yr}^{-1}$. Adding $\mathrm{CO}_{2}$ emissions from the drawdown area to the emissions from inundated areas as quantified in this study implies a global emission of $60.3(43.2-79.5) \mathrm{TgCO}_{2}-\mathrm{C} \mathrm{yr}^{-1}$. This increases the re-scaled current estimate of global $\mathrm{CO}_{2}$ emissions from reservoirs $\left(39.5(27.1-53.8) \mathrm{TgCO}_{2}-\mathrm{C} \mathrm{yr}^{-1}\right.$ (ref. $\left.{ }^{1}\right)$ ) by $53 \%$ (Cohen's D effect size $=2.6$; Table 1 and Fig. 3).

Total reservoir $\mathrm{C}$ emissions are dominated by $\mathrm{CH}_{4}$ in terms of climate forcing ${ }^{1}$. $\mathrm{CH}_{4}$ emissions from drawdown areas, however, have been shown to be low compared with $\mathrm{CO}_{2}$ emissions, but data on $\mathrm{CH}_{4}$ emissions from drawdown areas are scarce ${ }^{12}$. Assuming zero $\mathrm{CH}_{4}$ emissions from drawdown areas would reduce current global $\mathrm{CH}_{4}$ emissions from reservoirs (12.7 (6.8-23.2) $\mathrm{TgCH}_{4}-\mathrm{Cyr}^{-}$ ${ }^{1}$ (ref. $\left.{ }^{1}\right)$ ) by $1.8 \mathrm{TgCH}_{4}-\mathrm{C} \mathrm{yr}^{-1}$ (Table 1 and Fig. 3). However, when expressed in terms of $\mathrm{CO}_{2}$ e of the three main GHGs emitted from reservoirs (that is, considering $\mathrm{CO}_{2}, \mathrm{CH}_{4}$ and $\mathrm{N}_{2} \mathrm{O}$, assuming a global warming potential for $\mathrm{CH}_{4}$ of 34 (ref. ${ }^{22}$ ) and for $\mathrm{N}_{2} \mathrm{O}$ of 298 (ref. $\left.{ }^{22}\right)$ ), no substantial change of total $\mathrm{CO}_{2} \mathrm{e}$ emissions from reservoirs can be detected given the uncertainty of the calculation (758.4 (484.3-1,235.3) to $745.4(491.9-1,174.3) \mathrm{TgCO}_{2}-\mathrm{C} \mathrm{yr}^{-1}$, 


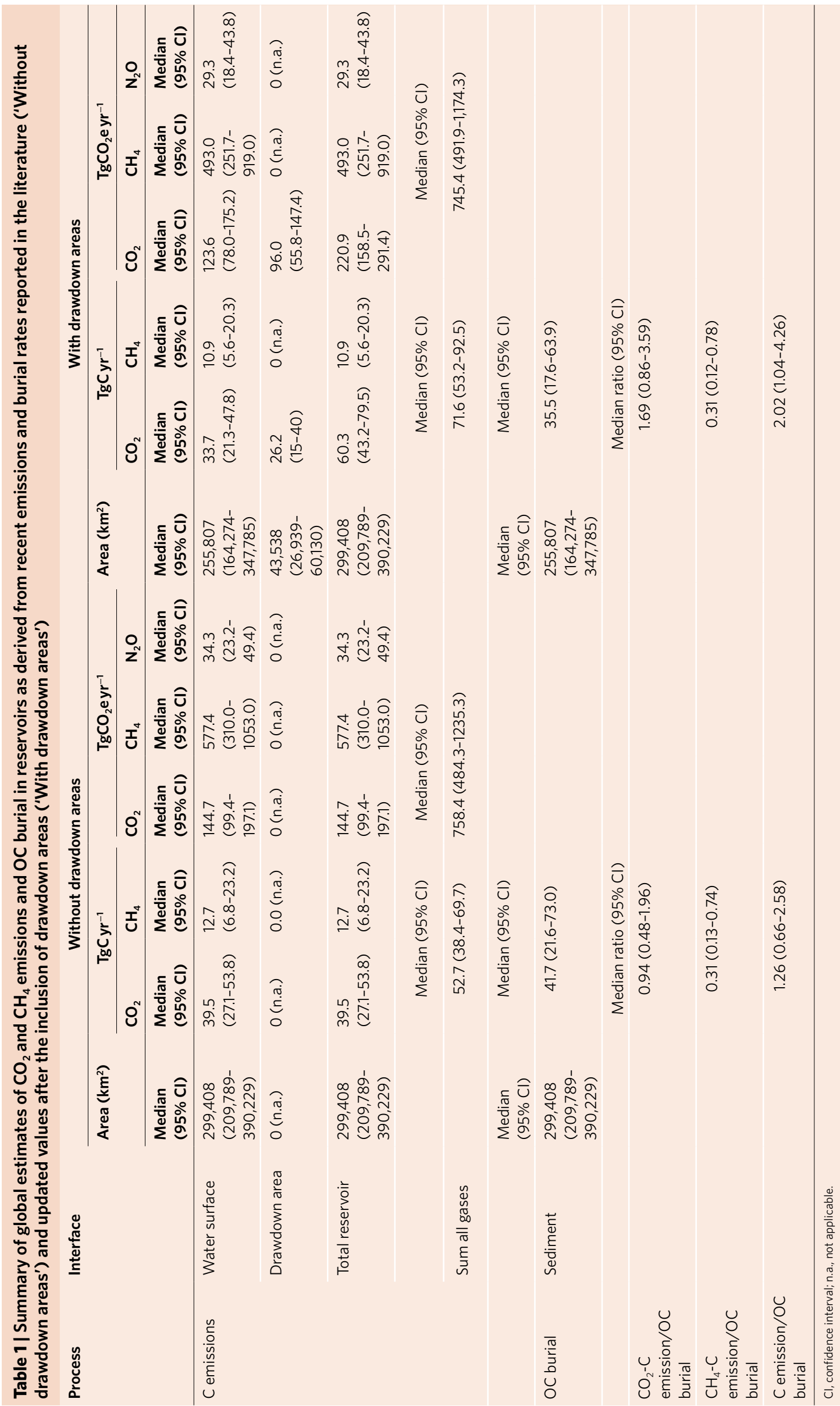



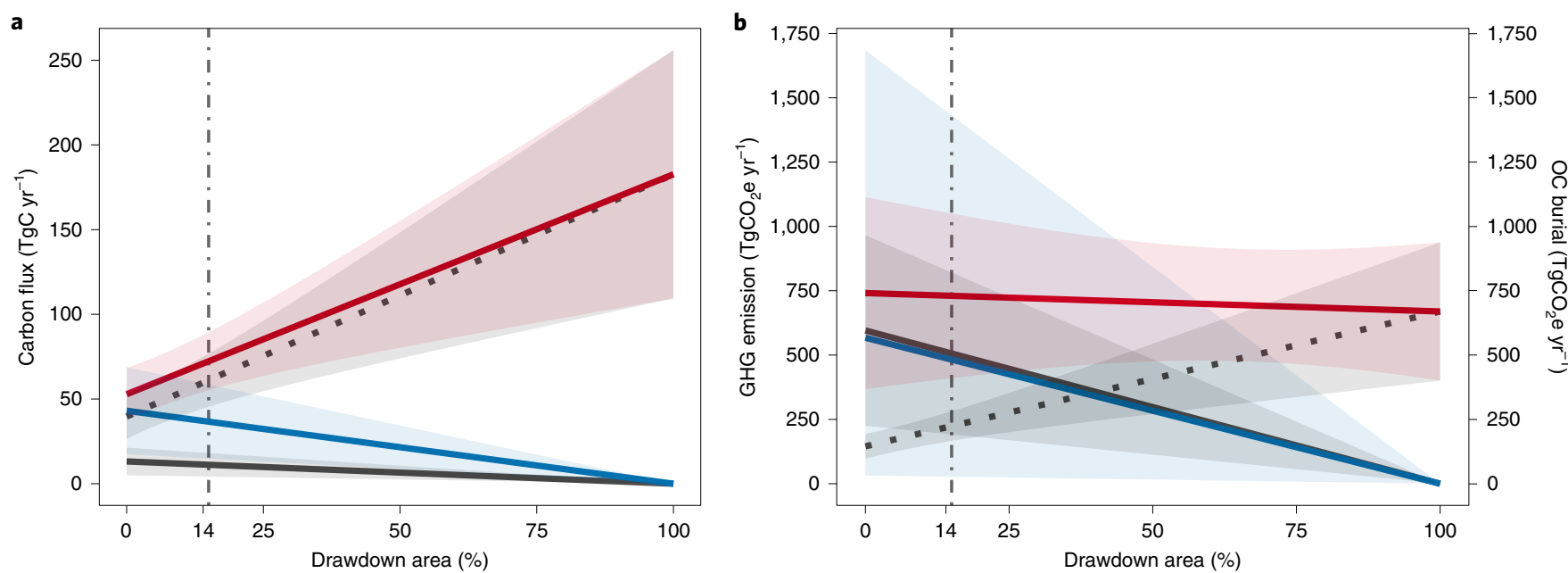

- $-\mathrm{CO}_{2}$ emission $=\mathrm{CH}_{4}$ emission $=$ Total emission burial

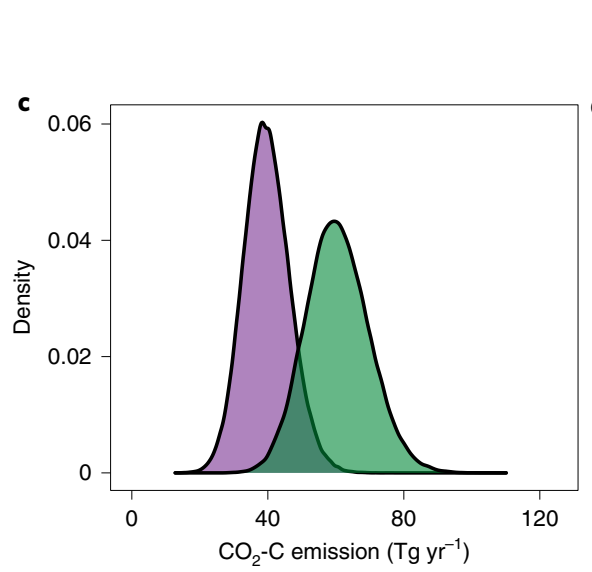

Without drawdown areas

Considering drawdown areas
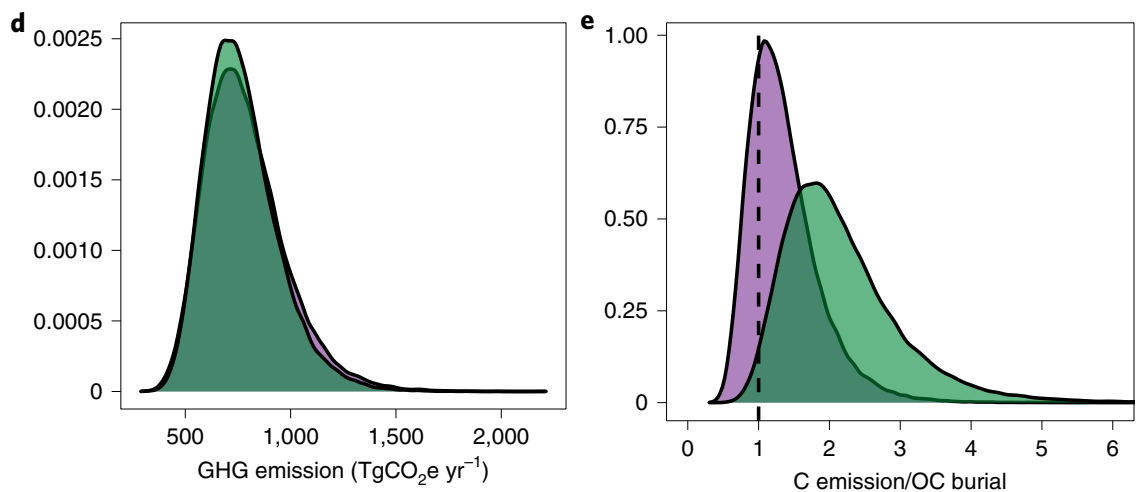

Fig. 3 | Gaseous $\mathbf{C}$ emissions and OC burial in global reservoirs. a, Emission and burial expressed as annual teragrams of $\mathbf{C}$. $\mathbf{b}$, Emission and burial expressed as $\mathrm{CO}_{2} \mathrm{e}$ fluxes. Green ribbon indicates the potential range of buried $\mathrm{CO}_{2} \mathrm{e}$ assuming conversion of OC between $100 \% \mathrm{CO}_{2}$ (lower bound) and $50 \%$ both $\mathrm{CO}_{2}$ and $\mathrm{CH}_{4}$ (upper bound). $\mathbf{a}, \mathbf{b}, \mathrm{CO}_{2}$ and $\mathrm{CH}_{4}$ emission: emissions from reservoirs comprising both drawdown area and water surface. Total emission: sum of $\mathrm{CO}_{2}$ and $\mathrm{CH}_{4}$ emissions. Vertical dot-dashed line indicates current global estimate of reservoir drawdown (15\%). Shaded areas represent $95 \% \mathrm{Cl}$ s. c-e, Probability density functions as derived by Taylor series expansion and Monte Carlo uncertainty propagation. $\mathbf{c}, \mathrm{CO}_{2}-\mathrm{C}$ emission from global reservoirs (Cohen's D effect size $=2.6$ ). $\mathbf{d}, \mathrm{GHG}$ emission expressed as $\mathrm{CO}_{2}$ e fluxes (Cohen's $\mathrm{D}$ effect size $=0.1$ ). e, Ratio between $\mathrm{C}$ emission and $\mathrm{OC}$ burial in reservoirs (Cohen's $\mathrm{D}$ effect size $=1.2$ ). $\mathrm{C}$ emission is the sum of $\mathrm{CO}_{2}-\mathrm{C}$ and $\mathrm{CH}_{4}-\mathrm{C}$ emission. The dashed line indicates ratio $=1$. $\mathbf{c}-\mathbf{e}$, The estimate without drawdown area (red curve) is assuming the total reservoir area to be inundated while the blue curve is considering the desiccation of the drawdown area. Densities are derived by 100,000 Monte Carlo simulations (Extended Data Fig. 10).

Cohen's D effect size $=0.9$; Table 1 and Fig. 3). $\mathrm{CO}_{2} \mathrm{e}$ emissions are dominated by $\mathrm{CH}_{4}$ for drawdown areas smaller than $\sim 30 \%$ of total reservoir surface. Because this finding is based on assuming zero $\mathrm{CH}_{4}$ emissions from drawdown areas, the dominant role of $\mathrm{CH}_{4}$ will be even increased if future studies reveal substantial $\mathrm{CH}_{4}$ emissions linked to drawdown areas, potentially leading to a total increase in $\mathrm{CO}_{2} \mathrm{e}$ emissions. In fact, exposure of hypolimnetic sediments at extreme drawdown may be a substantial methane source at least in the short term ${ }^{16,17}$. Furthermore, substantial decrease of water levels in reservoirs is expected to increase $\mathrm{CH}_{4}$ emissions via ebullition due to lowering of the hydrostatic pressure ${ }^{23,24}$. Our analysis shows that $40 \%$ of reservoirs built before 1985 experienced extreme drawdown at least once. Indeed, water withdrawals from reservoirs globally have more than doubled since the 1960 s due to increased demand ${ }^{25}$. Our findings show that drawdown areas have to be considered for the global $\mathrm{C}$ budget of reservoirs but that we need more data for refining global upscalings of GHG emissions from reservoirs.
Future research also needs to constrain remaining uncertainties. Although a recent study reported no systematic difference of $\mathrm{CO}_{2}$ emissions from dry inland waters among climate zones, the variability of $\mathrm{CO}_{2}$ fluxes across locations has been shown to be substantial $^{11}$. Thus, data with better spatial coverage are required to allow for a more comprehensive geostatistical upscaling considering regional differences in both $\mathrm{CO}_{2}$ fluxes and drawdown-area extent. Analogously, more knowledge of the temporal variability of $\mathrm{C}$ emissions from drawdown areas is required to constrain the uncertainty induced by seasonal and long-term dynamics of $\mathrm{C}$ fluxes ${ }^{26}$. It was, for example, shown that $\mathrm{CO}_{2}$ fluxes from dry sediments increase with temperature ${ }^{11}$. Hence, emissions could be enhanced in regions where seasonal variability of the water level exposes an above-average extent of drawdown areas in seasons with conditions boosting $\mathrm{CO}_{2}$ emissions. Furthermore, drawdown areas with pronounced seasonal cycles of desiccation and reflooding could have a disproportionate effect on $\mathrm{C}$ emissions due to the seasonal resupply of fresh sediments containing more labile C. In addition, it is well 
known that the trophic state of reservoirs affects their water-bound GHG emissions ${ }^{27}$. One may argue that the trophic state also has an impact on emissions from the drawdown area, for example, due to sedimentation of labile OC from autotrophic production. While we combined global estimates of drawdown-area extent, $\mathrm{C}$ emissions and OC burial for a global reassessment of these estimates, refining our results to regional or local scales would require comprehensive studies measuring all these processes in single reservoirs. Unfortunately, the amount of data currently available precludes such an analysis. Finally, desiccation of sediments allows the emergence of terrestrial vegetation ${ }^{12}$, a typical feature of many reservoirs. The fate of the $\mathrm{C}$ temporarily stored in this vegetation upon reflooding (burial versus mineralization to $\mathrm{CO}_{2}$ and/or $\mathrm{CH}_{4}$ ) may affect the $\mathrm{C}$ budget of reservoirs, but again, current data available are too scarce to meaningfully incorporate this process in our calculations.

Carbon gases emitted from reservoirs to the atmosphere are recycled in the biosphere on contemporary time scales, while $\mathrm{C}$ stored in sediments enters the long-term geological cycle. Reservoirs have previously been shown to bury $\mathrm{C}$ at higher rates than do natural lakes $^{6}$. Total OC burial in reservoirs is estimated to be 41.7 (21.673.0) ${\mathrm{TgC} \mathrm{yr}^{-1} \text { by multiplying area-specific burial rates }}^{6}$ times global reservoir area (Methods and Supplementary Discussion). Thus, globally, reservoirs are assumed to emit $1.26(0.66-2.58)$ times the $\mathrm{C}$ they bury, an estimate that would not allow stating emissions are significantly larger than OC burial. However, considering the effect of drawdown areas on both emissions (including dry areas) and burial (subtracting dry areas from calculations) substantially increases the global emission-to-burial ratio to 2.02 (1.04-4.26) (Table 1 and Fig. 3). This is substantially different from the previous value (Cohen's $\mathrm{D}$ effect size $=1.2$ ) and implies an overturn of the $\mathrm{C}$ budget of reservoirs tilted now towards $\mathrm{C}$ emissions. It may be argued that it is unclear how the global OC burial may vary with changing reservoir surface area due to its complex system-specific dependencies (for example, sediment focusing, dependence on allochtonous production of organic matter, and particle transport), However, even assuming a non-reduced $\mathrm{OC}$ burial in the $\mathrm{C}$ budget, consideration of drawdown areas on $\mathrm{C}$ emissions increases the emission-to-burial ratio to 1.72 (0.91-3.49) (not shown in Table 1). Hence, including drawdown areas in the global $\mathrm{C}$ budget of reservoirs is expected to shift the $\mathrm{C}$ mass balance towards $\mathrm{C}$ emission with emissions substantially exceeding OC burial, especially if global drawdown areas increase in the future (Fig. 3). In this respect, reservoirs become more similar to natural lakes, where OC burial represents $\sim 20 \%$ of C emissions ${ }^{6}$.

\section{Implications for further environmental services}

The relevance of drawdown areas on the $\mathrm{C}$ footprint of reservoirs suggests that water-level management (for example, avoiding drawdown in the dry season) could be a promising tool to control $\mathrm{C}$ emissions from reservoirs and minimize this source of GHGs. However, reservoir drawdown has further effects on the services these systems provide to humans that should be taken into account. For example, exposure of sediments can have additional effects on water quality beyond GHG emissions, such as enhanced phosphorus release from exposed sediments on reflooding, which lead to recommendations for avoiding drawdown events during summer ${ }^{28}$. Extreme drawdown events during summer also pose a threat to fish communities and water quality in general ${ }^{29,30}$, and many leisure activities (boating, angling) and aesthetic values from reservoirs would also benefit from a management strategy avoiding drawdown events during summer. However, the provision of drinking water, irrigation or hydropower may not be compatible with keeping high water levels during the dry period. In any case, decisions on water-level management in reservoirs usually require finding trade-offs between multiple uses and environmental considerations; thus, general recommendations should not be given lightly.

\section{Online content}

Any methods, additional references, Nature Research reporting summaries, source data, extended data, supplementary information, acknowledgements, peer review information; details of author contributions and competing interests; and statements of data and code availability are available at https://doi.org/10.1038/ s41561-021-00734-z.

Received: 16 June 2020; Accepted: 12 March 2021; Published online: 13 May 2021

\section{References}

1. Deemer, B. R. et al. Greenhouse gas emissions from reservoir water surfaces: a new global synthesis. BioScience 66, 949-964 (2016).

2. Aguilera, E. et al. Methane emissions from artificial waterbodies dominate the carbon footprint of irrigation: a study of transitions in the food-energywater-climate nexus (Spain, 1900-2014). Environ. Sci. Technol. 53, 5091-5101 (2019)

3. Barros, N. et al. Carbon emission from hydroelectric reservoirs linked to reservoir age and latitude. Nat. Geosci. 4, 593-596 (2011).

4. Li, S., Zhang, Q., Bush, R. T. \& Sullivan, L. A. Methane and $\mathrm{CO}_{2}$ emissions from China's hydroelectric reservoirs: a new quantitative synthesis. Environ. Sci. Pollut. Res. 22, 5325-5339 (2015).

5. Prairie, Y. T. et al. Greenhouse gas emissions from freshwater reservoirs: what does the atmosphere see? Ecosystems 21, 1058-1071 (2018).

6. Mendonça, R. et al. Organic carbon burial in global lakes and reservoirs. Nat. Commun. 8, 1694 (2017).

7. Thornton, K. W., Kimmel, B. L. \& Payne, F. E. (eds) Reservoir Limnology: Ecological Perspectives (Wiley, 1990).

8. Geraldes, A. M. \& Boavida, M.-J. Seasonal water level fluctuations: implications for reservoir limnology and management. Lakes Reserv. 10, 59-69 (2005).

9. Straskraba, M., Tundisi, J. G. \& Duncan, A. (eds) Comparative Reservoir Limnology and Water Quality Management (Springer, 1993).

10. Buendia, E. C. et al. (eds) 2019 Refinement to the 2006 IPCC Guidelines for National Greenhouse Gas Inventories (IPCC, 2019).

11. Keller, P. S. et al. Global $\mathrm{CO}_{2}$ emissions from dry inland waters share common drivers across ecosystems. Nat. Commun. 11, 2126 (2020).

12. Marcé, R. et al. Emissions from dry inland waters are a blind spot in the global carbon cycle. Earth Sci. Rev. 188, 240-248 (2019).

13. Yang, M. et al. Spatial and seasonal $\mathrm{CH}_{4}$ flux in the littoral zone of Miyun Reservoir near Beijing: the effects of water level and its fluctuation. PLoS One 9, e94275 (2014).

14. Almeida, R. M. et al. Carbon dioxide emission from drawdown areas of a Brazilian reservoir is linked to surrounding land cover. Aquat. Sci. 81, 68 (2019)

15. Deshmukh, C. et al. Carbon dioxide emissions from the flat bottom and shallow Nam Theun 2 Reservoir: drawdown area as a neglected pathway to the atmosphere. Biogeosciences 15, 1775-1794 (2018).

16. Kosten, S. et al. Extreme drought boosts $\mathrm{CO}_{2}$ and $\mathrm{CH}_{4}$ emissions from reservoir drawdown areas. Inland Waters 8, 329-340 (2018).

17. Jin, H. et al. Enhanced greenhouse gas emission from exposed sediments along a hydroelectric reservoir during an extreme drought event. Environ. Res. Lett. 11, 124003 (2016).

18. Zhao, G. \& Gao, H. Automatic correction of contaminated images for assessment of reservoir surface area dynamics. Geophys. Res. Lett. 45, 6092-6099 (2018).

19. Lehner, B. et al. High-resolution mapping of the world's reservoirs and dams for sustainable river-flow management. Front. Ecol. Environ. 9, 494-502 (2011).

20. Ryan, J. C., Smith, L. C., Cooley, S. W., Pitcher, L. H. \& Pavelsky, T. M. Global characterization of inland water reservoirs using ICESat-2 altimetry and climate reanalysis. Geophys. Res. Lett. 47, e2020GL088543 (2020).

21. Maxmen, A. As Cape Town water crisis deepens, scientists prepare for 'Day Zero'. Nature 554, 13-14 (2018).

22. Myhre, G. et al. in Climate Change 2013: The Physical Science Basis (eds Stocker, T. F. et al.) 659-740 (IPCC, Cambridge Univ. Press, 2013).

23. Beaulieu, J. J. et al. Effects of an experimental water-level drawdown on methane emissions from a eutrophic reservoir. Ecosystems 21, 657-674 (2018).

24. Harrison, J. A., Deemer, B. R., Birchfield, M. K. \& O’Malley, M. T. Reservoir water-level drawdowns accelerate and amplify methane emission. Environ. Sci. Technol. 51, 1267-1277 (2017).

25. Hofste, R., Kuzma, S., Walker, S. \& Sutanudjaja, E. H. Aqueduct 3.0: Updated Decision-Relevant Global Water Risk Indicators (World Resources Institute, 2019); https://www.wri.org/publication/aqueduct-30 
26. Martinsen, K. T., Kragh, T. \& Sand-Jensen, K. Carbon dioxide fluxes of air-exposed sediments and desiccating ponds. Biogeochemistry 144, 165-180 (2019).

27. DelSontro, T., Beaulieu, J. J. \& Downing, J. A. Greenhouse gas emissions from lakes and impoundments: upscaling in the face of global change. Limnol. Oceanogr. Lett. 3, 64-75 (2018).

28. Watts, C. J. Seasonal phosphorus release from exposed, re-inundated littoral sediments of two Australian reservoirs. Hydrobiologia 431, 27-39 (2000).

29. Marcé, R. \& Armengol, J. in Water Scarcity in the Mediterranean: Perspectives Under Global Change (eds Sabater, S. \& Barceló, D.) 73-94 (Springer, 2010).

30. Shantz, M. et al. The effect of drawdown on suspended solids and phosphorus export from Columbia Lake, Waterloo, Canada. Hydrol. Process. 18, 865-878 (2004).

31. Pekel, J.-F., Cottam, A., Gorelick, N. \& Belward, A. S. High-resolution mapping of global surface water and its long-term changes. Nature 540, 418-422 (2016).
Publisher's note Springer Nature remains neutral with regard to jurisdictional claims in published maps and institutional affiliations.

(c) (i)

Open Access This article is licensed under a Creative Commons

Attribution 4.0 International License, which permits use, sharing, adaptation, distribution and reproduction in any medium or format, as long as you give appropriate credit to the original author(s) and the source, provide a link to the Creative Commons license, and indicate if changes were made. The images or other third party material in this article are included in the article's Creative Commons license, unless indicated otherwise in a credit line to the material. If material is not included in the article's Creative Commons license and your intended use is not permitted by statutory regulation or exceeds the permitted use, you will need to obtain permission directly from the copyright holder. To view a copy of this license, visit http://creativecommons. org/licenses/by/4.0/.

(C) The Author(s) 2021 


\section{Methods}

Data for estimating drawdown areas. The calculation of drawdown areas was based on monthly time series of surface-area values for 6,818 reservoirs provided by GRSAD ${ }^{18}$. It comprises all reservoirs from the Global Reservoir and Dam dataset ${ }^{19}$ except of 45 reservoirs without reported geometric information. In accordance with ref. ${ }^{1}$, we further removed 24 reservoirs classified as natural lakes that have been modified with water regulation structures (this includes lakes Victoria, Baikal and Ontario). The GRSAD dataset comprised entries from March 1984 to October 2015. To have a constant number of data points per year, we restricted our analysis to the period from January 1985 to December 2014

GRSAD was created by correcting the Global Surface Water dataset ${ }^{31}$ for images contaminated with clouds, cloud shadows and terrain shadows. With this correction, the number of effective images that can be used in each time series has been increased by $81 \%$ on average. Substantial improvements have been achieved for reservoirs located in regions with frequent cloud cover and high-latitude reservoirs in the Northern Hemisphere, where low illumination has previously resulted in missing area values during winter months.

Calculation of drawdown areas. We calculated monthly drawdown areas for all reservoirs contained in GRSAD according to:

$$
\mathrm{DA}=\left(\text { Area }_{\max }-\text { Area }\right) / \text { Area }_{\max }
$$

where DA is the relative extent of the drawdown area for a given reservoir considering the current monthly surface area (Area) and the maximum area recorded during the period 1985-2015 (Area $\left.\mathrm{max}_{\mathrm{max}}\right)$. We assumed that the maximum area of each reservoir recorded during the 30 -year period is a valid representation of its nominal surface area (the area of the reservoir at maximum filling level).

Complete filling of reservoirs was defined by a drawdown area smaller than $5 \%$ of Area $_{\max }$. Because there is no uniform definition of 'extreme drawdown', we used the Cape Town water crisis 2018 as a reference ${ }^{21}$. The number of reservoirs experiencing extreme drawdown was estimated by averaging the number of reservoirs with drawdown areas exceeding $40 \%, 50 \%, 60 \%$ or $70 \%$ of Area at least once. To prevent initial filling of reservoirs being identified as extreme drawdown, 791 reservoirs built during the analysed period (year built $\geq 1985$ ) were excluded from this analysis. The upper bound (70\%) corresponds to the drawdown-area extent during the Cape Town water crisis $2018^{21}$ (Fig. 1a). The lower bound $(40 \%)$ corresponds to a reservoir capacity (storage water volume) of approximately $35 \%$, as remained available during that water crisis, assuming an idealized, triangular reservoir shape (Extended Data Fig. 8). This was estimated according to:

$$
0.36=\frac{(0.6 \times \sqrt{2})^{2}}{2}
$$

For the calculation of total global drawdown area, used for the upscaling of GHG emissions, we combined data for reservoirs larger than $10 \mathrm{~km}^{2}$ with values derived from a Pareto model for smaller reservoirs. First, we estimated total reservoir surface area for nine size classes following a Pareto distribution. Subsequently, we estimated total drawdown area for each size class by multiplying the size-class-specific relative drawdown-area extent by the total reservoir surface area of each size class (Supplementary Table 3). Because the relative drawdown-area extent for reservoirs smaller than $0.001 \mathrm{~km}^{2}$ is unknown and furthermore considered as being imprecise for reservoirs smaller than $10 \mathrm{~km}^{2}$, we derived estimates for these size classes on the basis of four different statistical models (linear, square root, logarithmic, polynomial; Extended Data Fig. 9). Reservoirs larger than $10 \mathrm{~km}^{2}$ were used to fit linear, square root and logarithmic models, whereas all available data were used for fitting a second-degree polynomial model to achieve a best representation of the available data. The four models all have a constant (linear model) or decreasing (square root, logarithmic, polynomial) slope. We have refrained from using models with increasing slopes (for example, exponential) to not overestimate the drawdown extent of small reservoirs and, thus, consider these estimates as conservative.

Data analysis. Statistical models to predict drawdown-area extent for each reservoir were developed using stepwise MLR. Climatic data (mean annual temperature, precipitation seasonality) for all reservoir locations were extracted from the Climatologies at High Resolution for the Earth's Land Surface Areas climate dataset, which gives high-resolution $(0.5 \mathrm{arcmin})$ climate information for global land areas over the period 1979-2013 32 . Climate zones in the KöppenGeiger system were determined from the high-resolution ( $5 \mathrm{arcmin}$ ) global climate map derived from long-term monthly precipitation and temperature time series representative for the period 1986-2010 ${ }^{33,34}$. Data on baseline water stress were extracted from Aqueduct $3.0^{25}$. Baseline water stress measures the ratio of total water withdrawals to available renewable surface and groundwater supplies and is derived from high-resolution ( $5 \mathrm{arcmin}$ ) hydrological model outputs using the PCR-GLOBWB 2 model $^{35,36}$.

Dates were categorized into four seasons on the basis of their meteorological definition depending on hemisphere. Therefore, for the Northern Hemisphere, spring begins on 1 March, summer on 1 June, autumn on 1 September and winter on 1 December. For the Southern Hemisphere, spring begins on 1 September, summer on 1 December, autumn on 1 March and winter on 1 June.

For the analyses of reservoir use types, we used the information provided in the column 'MAIN_USE' of the Global Reservoir and Dam dataset. Reservoirs where the main use was not specified $(n=1,554)$ were combined with those having MAIN_USE $=$ 'Other' $(n=205)$.

To identify the magnitude of trends in time series, we used the non-parametric Theil-Sen estimator and the Mann-Kendall test because they do not require prior assumptions of statistical distribution for the data and are resistant to outliers. The Theil-Sen estimator was used to compute the linear rate of change, and the Mann-Kendall test was used to determine the level of significance. We analysed differences between groups using the Kruskal-Wallis test and Dunn's post hoc test. The threshold to assess statistical significance was 0.05 for all analyses, The statistical analyses were performed using R $3.4 .4^{37}$

Upscaling of GHG emissions and OC burial. Because the global reservoir area derived in this study differed from the area used in previous studies, we recalculated the published global estimates for both OC burial ${ }^{6}$ in and GHG emissions ${ }^{1}$ from reservoirs to allow for comparison (Extended Data Fig. 10). We fitted empirical distributions to $\mathrm{CO}_{2}$ emission data from drawdown areas (Supplementary Table 2 and Extended Data Fig. 7) as well as the published OC burial rates ${ }^{6}$ and published GHG emission data ${ }^{1}$ from water surfaces of reservoirs. For $\mathrm{CO}_{2}$ emissions from drawdown areas, we used a gamma distribution to account for non-normality of the data (Extended Data Fig. 7). For $\mathrm{CO}_{2}$ and $\mathrm{N}_{2} \mathrm{O}$ emissions from the water surface, we fitted a skewed normal distribution because of the occurrence of negative values (Extended Data Fig. 7). For $\mathrm{CH}_{4}$ emissions from the water surface, we fitted a log-normal distribution (Extended Data Fig. 7). Because the global estimate of OC burial was derived using geostatistical modelling, we fitted a gamma distribution to the published moments of OC burial rate $^{6}\left(\right.$ mean \pm s.d. $=144 \pm 75.83 \mathrm{gC} \mathrm{m}^{-2} \mathrm{yr}^{-1}$ ) where the s.d. is calculated as the s.d. of the four scenarios used in that study. The final global empirical distributions for all fluxes were estimated by multiplying average emission and burial rates derived from resampling the preceding distributions times the total water surface area and drawdown area of reservoirs, resulting also from resampling their distributions after uncertainty propagation (see Treatment of uncertainty).

Treatment of uncertainty. As in all upscaling exercises, the global analysis conducted in this study is subject to substantial uncertainty. In our case, the uncertainty results from both the quantification of water surface and drawdown area of reservoirs and the estimation of global rates for GHG emission and OC burial. To comprehensively take all sources of uncertainty into account, we propagated all uncertainty throughout the whole analysis using a combination of Taylor series expansion and Monte Carlo simulations (Extended Data Fig. 10). In brief, we applied customary equations for uncertainty propagation derived from the Taylor series expansion method when propagating uncertainty of moments (for example, mean) or simple arithmetic calculations (for example, multiplication). For more-complex situations or when non-normality was conspicuous, we used Monte Carlo propagation. To obtain global estimates and standard error of water surface and drawdown area of reservoirs, both the systematic (bias) and random uncertainties of the remote-sensing-derived dataset ${ }^{18}$ as well as the uncertainty induced by our Pareto modelling for reservoirs $<10 \mathrm{~km}^{2}$ were propagated through all arithmetic calculations. These estimates and their uncertainty were again propagated to the calculation of global GHG flux and burial rates by combining them with rates and uncertainties derived from empirical distributions as described in the preceding. In a final step, Monte Carlo propagations were used to calculate the emission-to-burial ratios. All instances of Monte Carlo propagation were performed with 100,000 simulations by using the $\mathrm{R}$ package propagate ${ }^{38}$.

\section{Data availability}

The GRSAD dataset containing the surface-area time series of 6,818 global reservoirs is available online at https://doi.org/10.18738/T8/DF80WG. The CHELSA climate dataset, which gives high-resolution climate information for global land areas is available online at https://chelsa-climate.org/. Data on climate zones according to the Köppen-Geiger classification are available at http:// koeppen-geiger.vu-wien.ac.at/. Data on baseline water stress extracted from Aqueduct 3.0 are available at https://www.wri.org/publication/aqueduct-30. Source data are provided with this paper.

\section{Code availability}

Scripts used for the analyses described in this study can be obtained from the corresponding author upon request.

\section{References}

32. Karger, D. N. et al. Climatologies at high resolution for the Earth's land surface areas. Sci. Data 4, 170122 (2017). 
33. Kottek, M., Grieser, J., Beck, C., Rudolf, B. \& Rubel, F. World Map of the Köppen-Geiger climate classification updated. Meteorol. Z. 15 259-263 (2006).

34. Rubel, F., Brugger, K., Haslinger, K. \& Auer, I. The climate of the European Alps: shift of very high resolution Köppen-Geiger climate zones 1800-2100. Meteorol. Z. 26, 115-125 (2017).

35. Sutanudjaja, E. H. et al. PCR-GLOBWB 2: a 5 arcmin global hydrological and water resources model. Geosci. Model Dev. 11, 2429-2453 (2018).

36. Wada, Y., Wisser, D. \& Bierkens, M. F. P. Global modeling of withdrawal, allocation and consumptive use of surface water and groundwater resources. Earth Syst. Dyn. 5, 15-40 (2014).

37. R Core Team. R: A Language and Environment for Statistical Computing (R Foundation for Statistical Computing, 2018).

38. Spiess, A.-N. propagate: Propagation of Uncertainty (2018); https:// CRAN.R-project.org/package= propagate

\section{Acknowledgements}

P.S.K. and M.K. were financially supported by the German Research Foundation (project TregaTa KO 1911/6-1), B.O. and R.M. by the project C-HydroChange, funded by the Spanish Agencia Estatal de Investigación (AEI) and Fondo Europeo de Desarrollo Regional (FEDER) under the contracts FEDER-MCIU-AEI/ CGL2017-86788-C3-2-P and CGL2017-86788-C3-3-P. R.M. acknowledges funding from Generalitat de Catalunya through the Consolidated Research Group 2017SGR1124 and the CERCA programme. We thank K. Rinke and X. Kong for their thoughts about the study.

\section{Author contributions}

P.S.K. and M.K. designed the study. P.S.K. performed the data analyses with notable contribution by R.M.; P.S.K. wrote the first draft of the manuscript. P.S.K., B.O., R.M. and M.K. contributed to manuscript writing and editing.

\section{Competing interests}

The authors declare no competing interests.

\section{Additional information}

Extended data is available for this paper at https://doi.org/10.1038/s41561-021-00734-z. Supplementary information The online version contains supplementary material available at https://doi.org/10.1038/s41561-021-00734-z.

Correspondence and requests for materials should be addressed to P.S.K.

Peer review information Nature Geoscience thanks Ronny Lauerwald, Jacqueline Webb and the other, anonymous, reviewer(s) for their contribution to the peer review of this work. Primary Handling Editor: Tom Richardson.

Reprints and permissions information is available at www.nature.com/reprints. 


\section{NATURE GEOSCIENCE}

ARTICLES
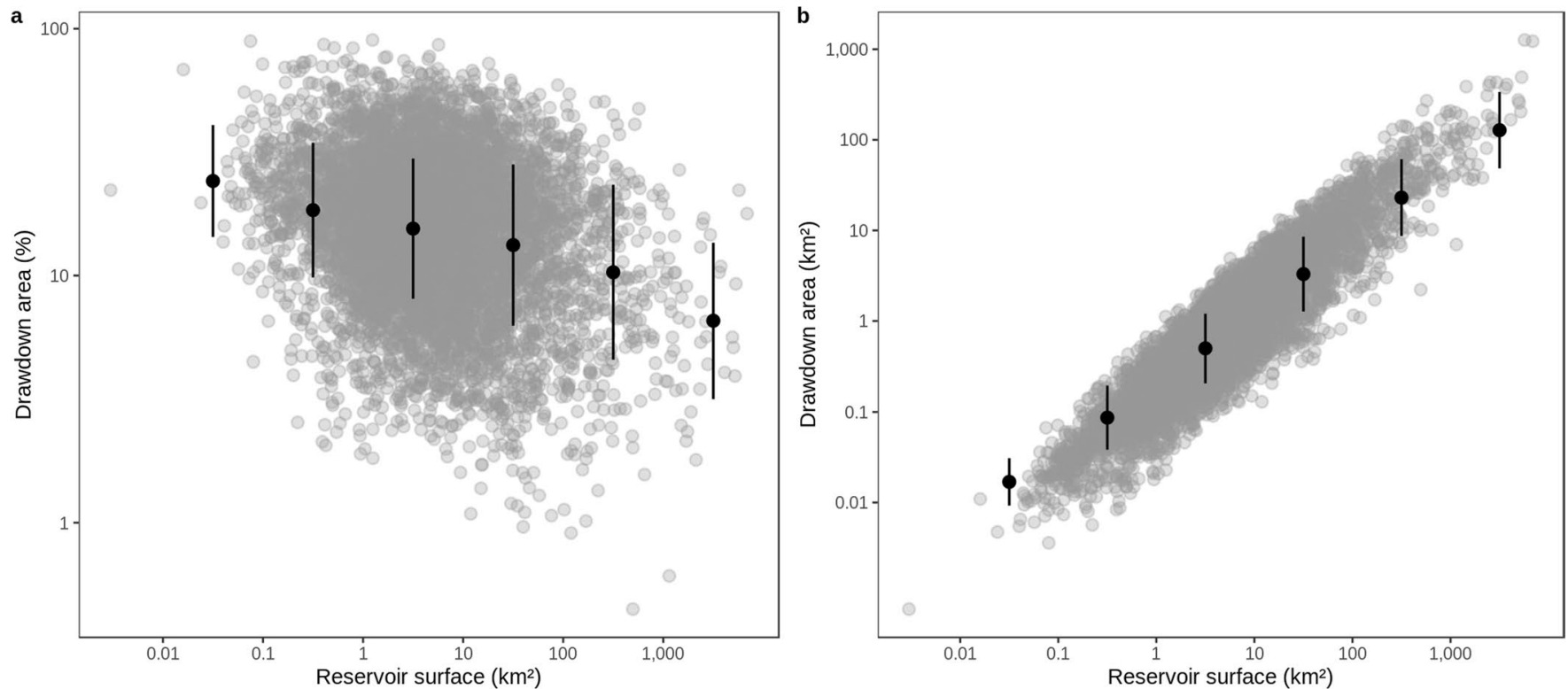

Extended Data Fig. 1 | Drawdown area depending on reservoir size. a Drawdown area relative to reservoir size. $\mathbf{b}$ Absolute drawdown area relative to reservoir size. $\mathbf{a} \& \mathbf{b}$ Black points show mean values and error bars their standard deviation. Each grey dot represents a reservoir. Note that drawdown area and reservoir surface are presented on $\log _{10}$ scale. 
ARTICLES

NATURE GEOSCIENCE

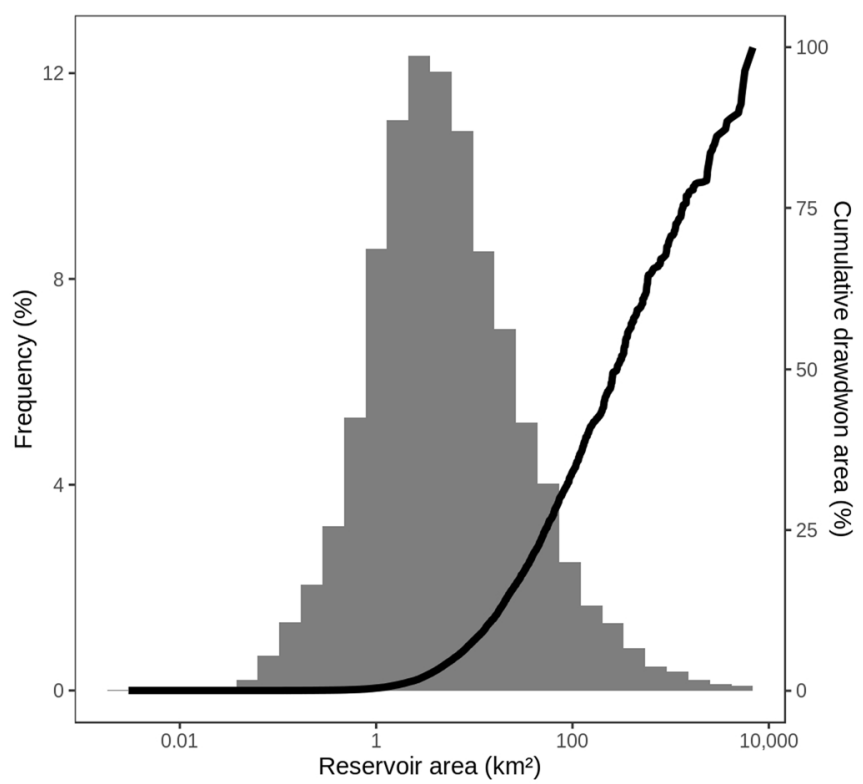

Extended Data Fig. 2 | Cumulative drawdown area (black line) and reservoir frequency (grey bars) depending on reservoir size. All reservoirs were ordered according to their size and the cumulative drawdown area was computed. Note that reservoir area is presented on $\log _{10} \mathrm{scale}_{\mathrm{e}}$

NATURE GEOSCIENCE | www.nature.com/naturegeoscience 


\section{NATURE GEOSCIENCE}

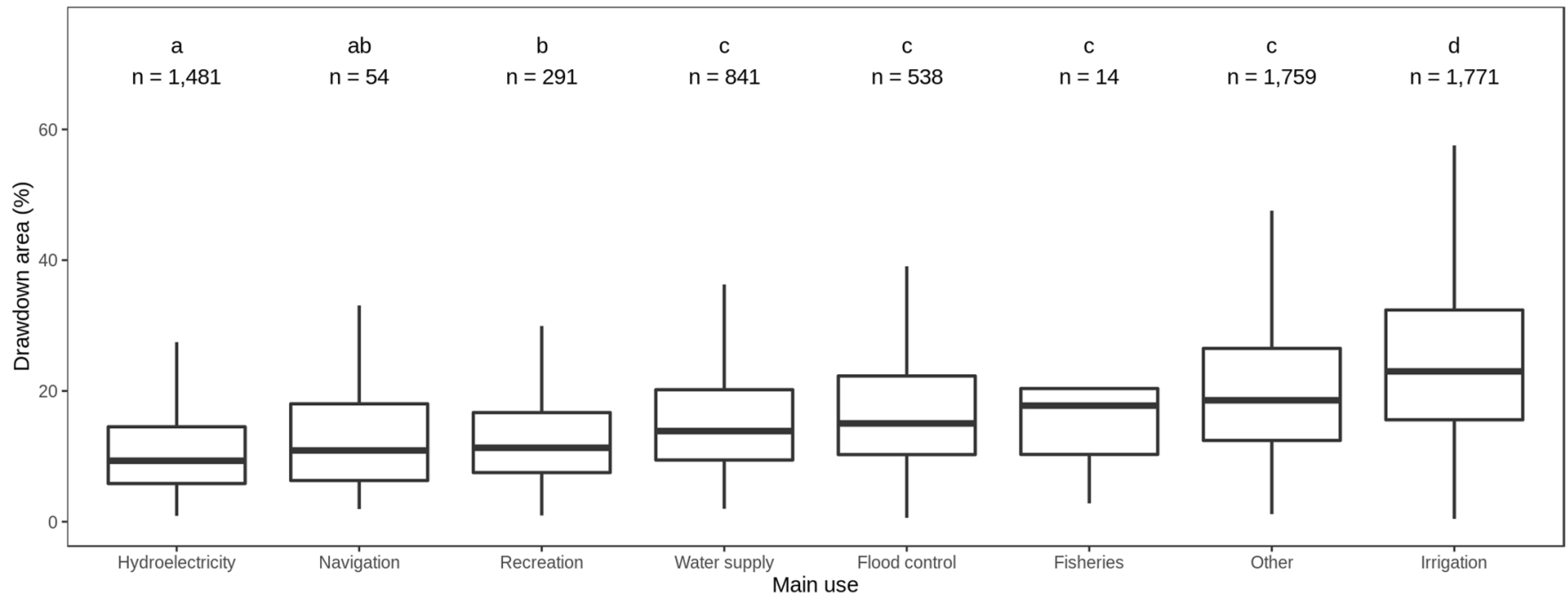

Extended Data Fig. 3 | Average drawdown areas of different types of reservoirs. Box $=25^{\text {th }}$ and $75^{\text {th }}$ percentiles, whiskers $=1.5^{*}$ inter-quartile range. Black line $=$ median. Letters indicate significant differences between groups. (Kruskal-Wallis test and Dunn's post hoc test, $p<0.05$ ). 

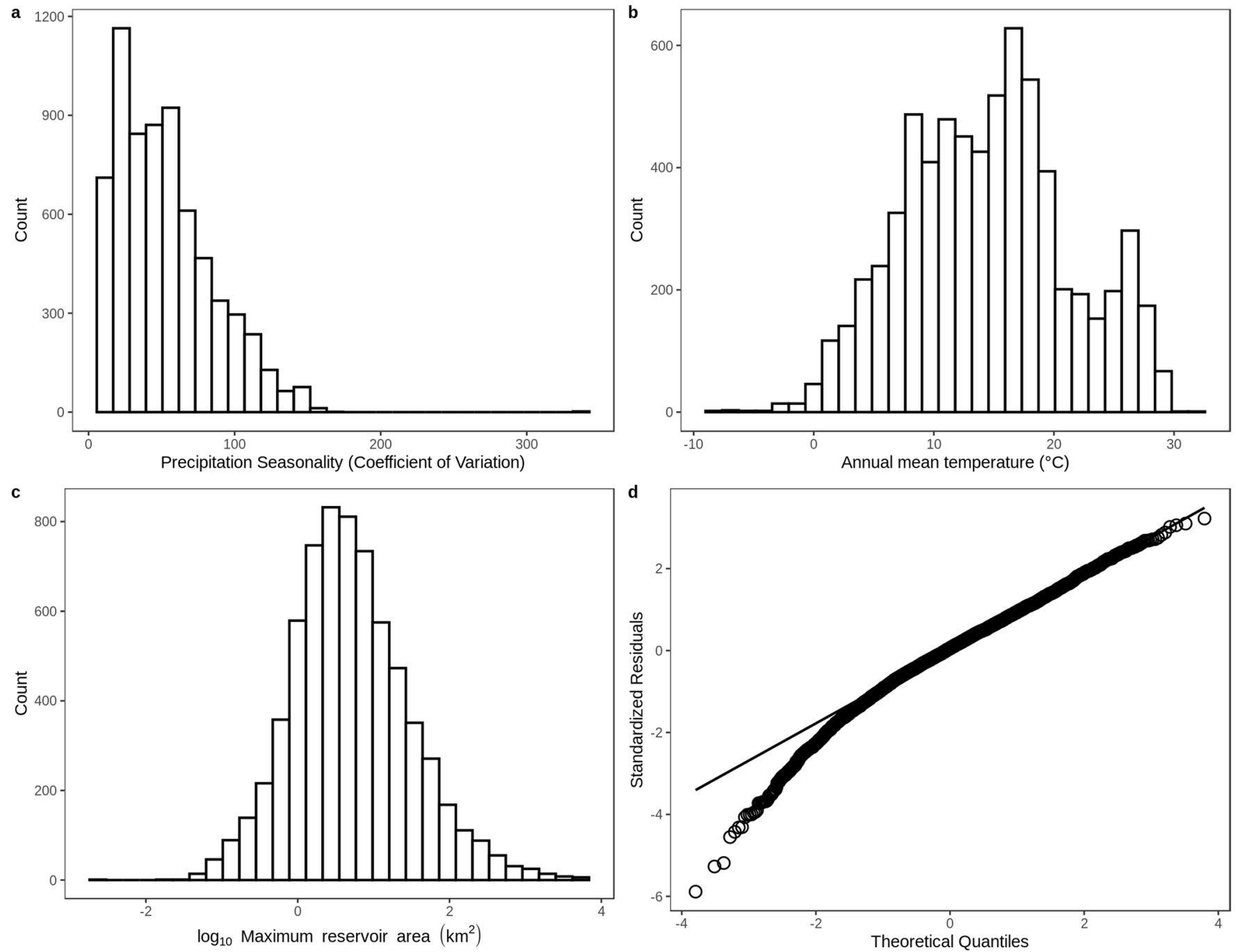

Extended Data Fig. 4 | Diagnostic plots for multiple linear regression model. Model details and estimates area presented in Supplementary Table 1. a-c, histograms of modelled continuous variables. c, Please note that maximum reservoir area is presented on $\log _{10}$ scale. d, Normal Q-Q plot of model's residuals. 


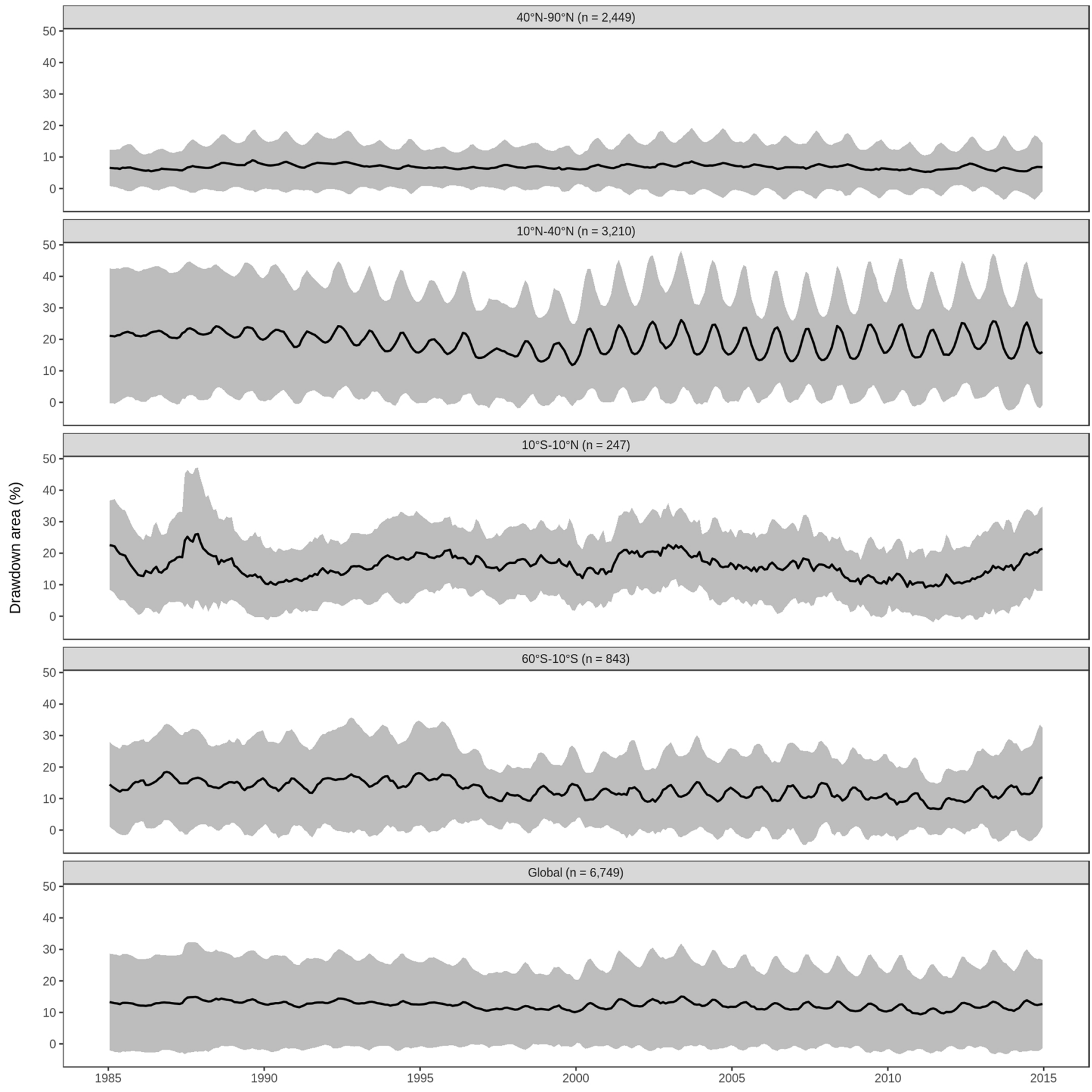

Extended Data Fig. 5 | Temporal development of drawdown area aggregated for latitudinal bins and the whole globe. Black line shows mean drawdown area extent as a percentage of the total reservoir area for each month. Grey ribbon indicates its standard deviation. 


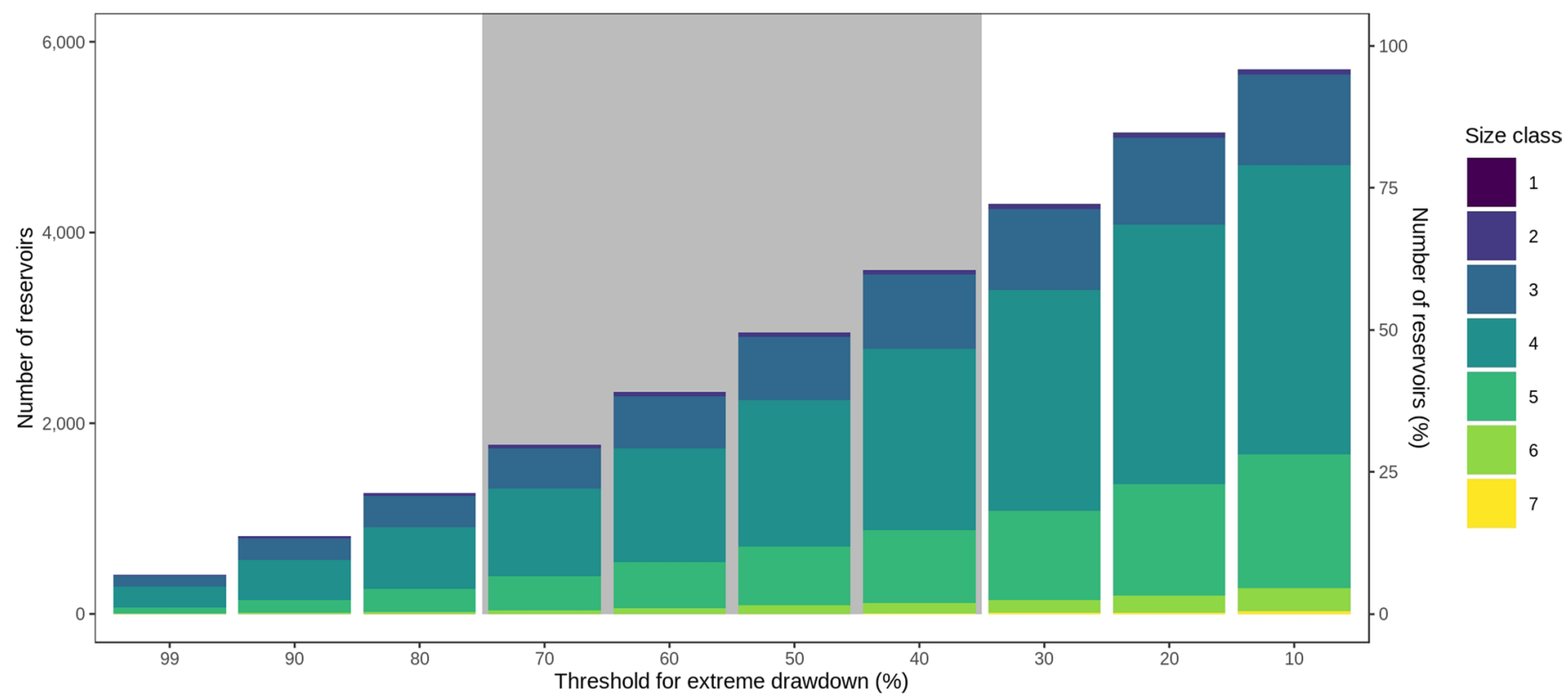

Extended Data Fig. 6 | Reservoirs experiencing extreme drawdown. 791 reservoirs built during analysed period were excluded $(n=5958)$. Threshold for extreme drawdown relates to extent of drawdown area relative to maximum filling level of reservoirs. Thresholds highlighted by grey area were used for analysis. Size class 1 contains reservoirs with surface area from 10,000 km²-100,000 km² size class 2: 1,000 km²-10,000 km²; size class 3: $100 \mathrm{~km}^{2}-$ $1,000 \mathrm{~km}^{2}$; size class 4: $10 \mathrm{~km}^{2}-100 \mathrm{~km}^{2}$; size class 5: $1 \mathrm{~km}^{2}-10 \mathrm{~km}^{2}$; size class 6: $0.1 \mathrm{~km}^{2}-1 \mathrm{~km}^{2}$; size class $7: 0.01 \mathrm{~km}^{2}-0.1 \mathrm{~km}^{2}$. 


\section{NATURE GEOSCIENCE}
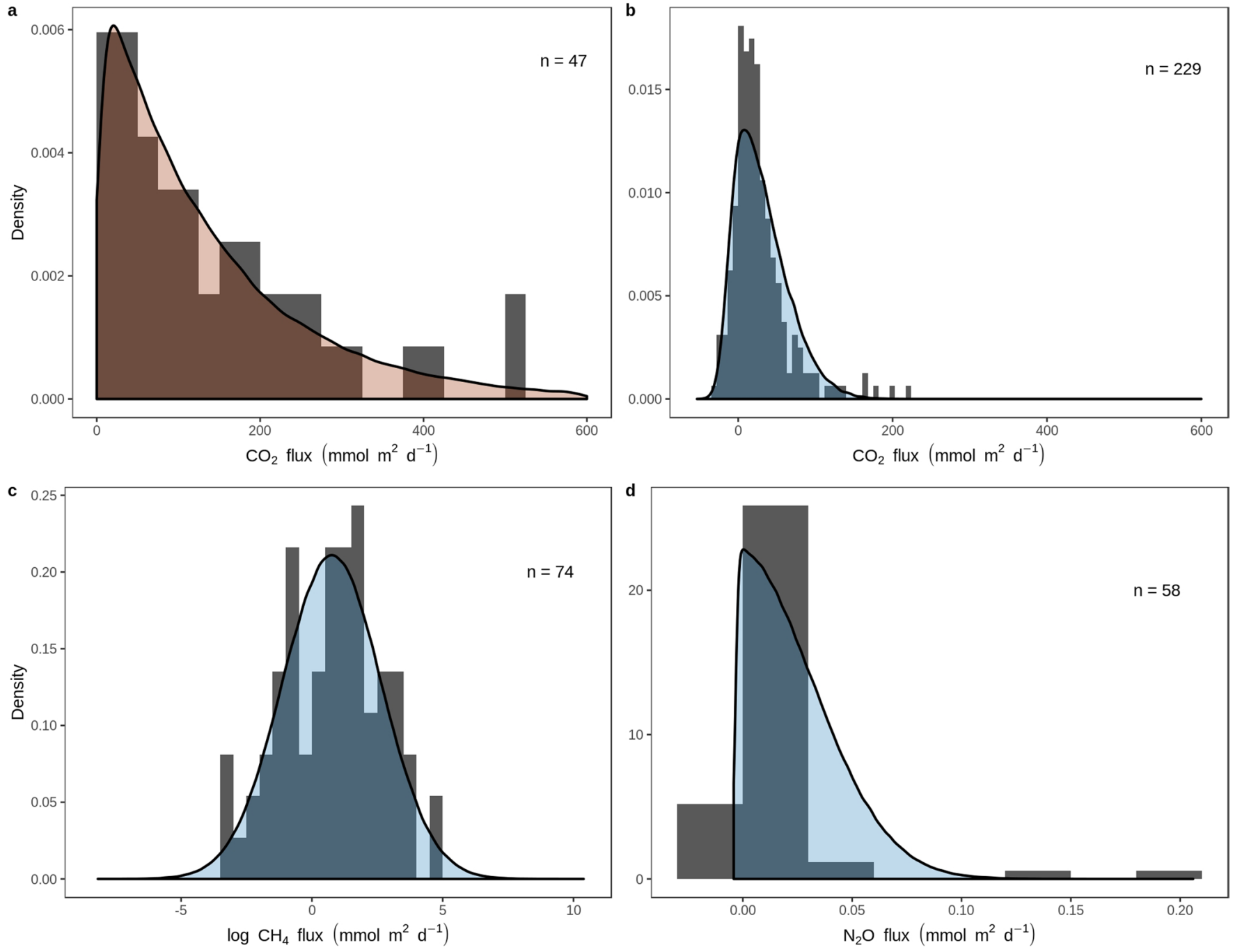

Extended Data Fig. 7 | Histograms of measured emissions rates and empirical probability density functions. a $\mathrm{CO}_{2}$ emission measured at the drawdown area (Supplementary Table 2) and fitted gamma distribution (brown curve). b-d $\mathrm{CO}_{2}, \mathrm{CH}_{4}$ and $\mathrm{N}_{2} \mathrm{O}$ emission from reservoirs' water surface'. b Published raw data (grey bars) and fitted skew-normal distribution (blue curve). c Published raw data (grey bars) and fitted log-normal distribution (blue curve). Please note that $\mathrm{CH}_{4}$ emission data is presented on log scale. e Published raw data (grey bars) and fitted skew-normal distribution (blue curve). 

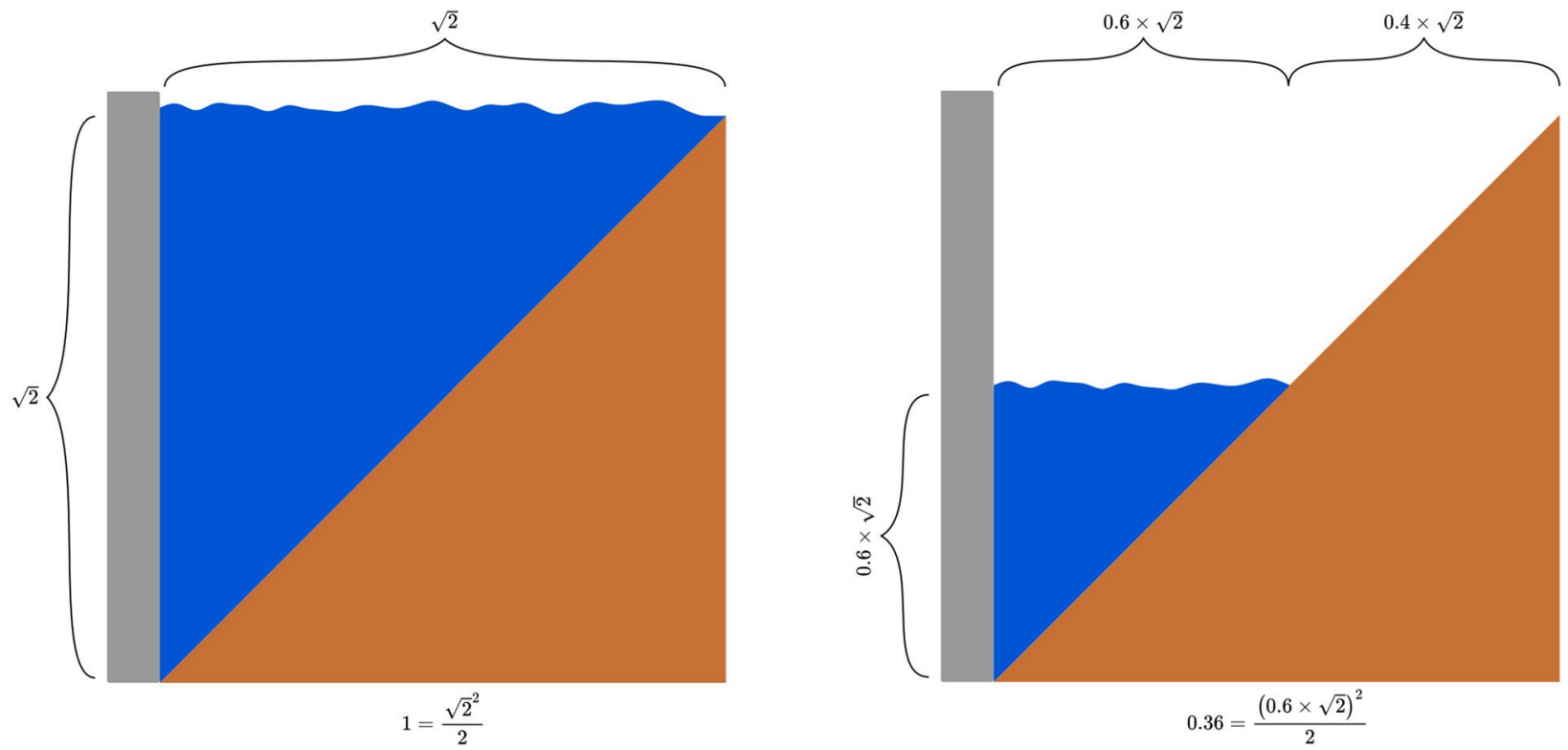

Extended Data Fig. 8 | Schematic illustration of extreme drawdown in an ideal, triangular Reservoir. Left: Reservoir completely filled with water; right: extreme drawdown at $36 \%$ reservoir capacity. 


\section{NATURE GEOSCIENCE}

a
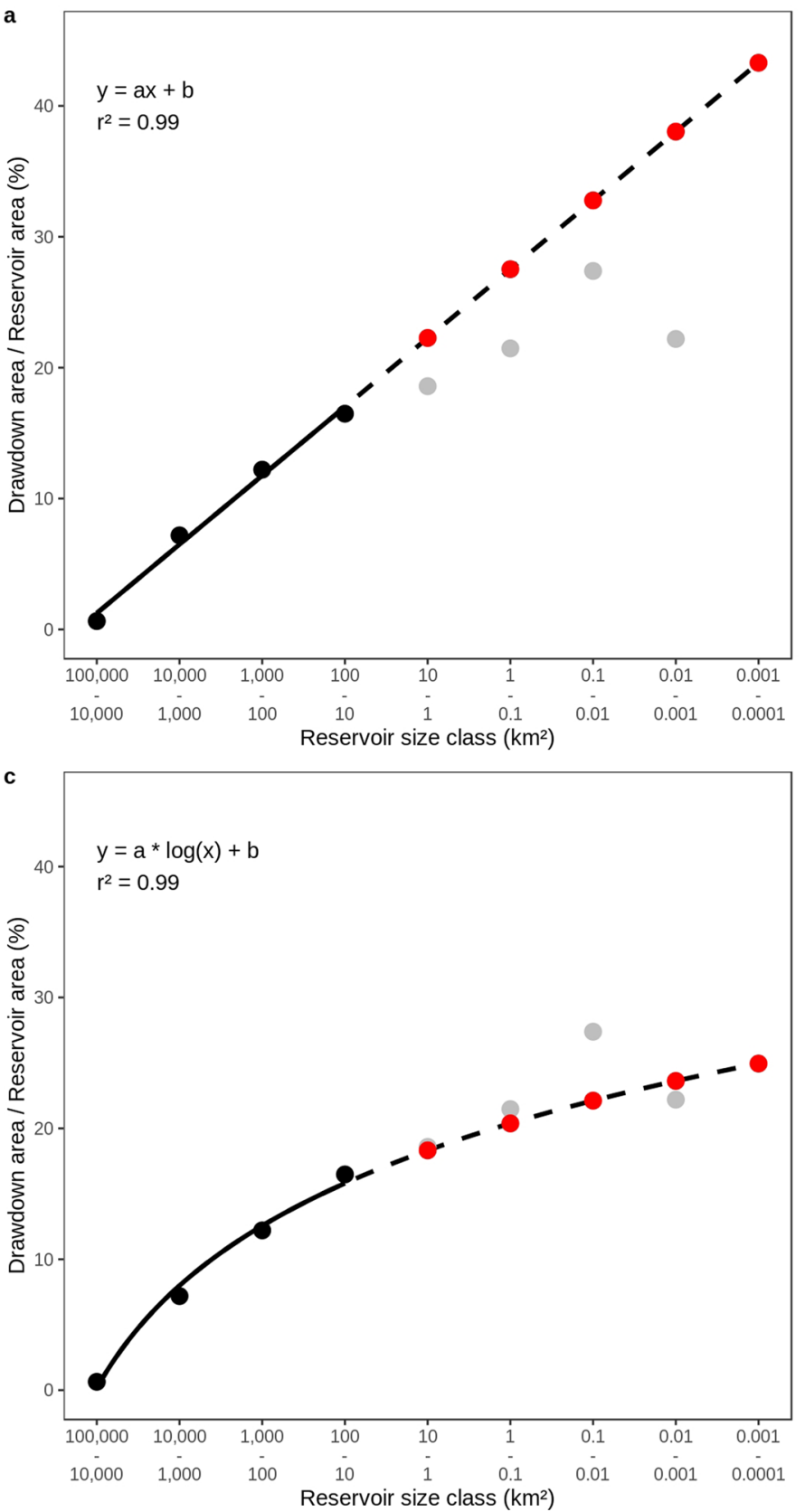

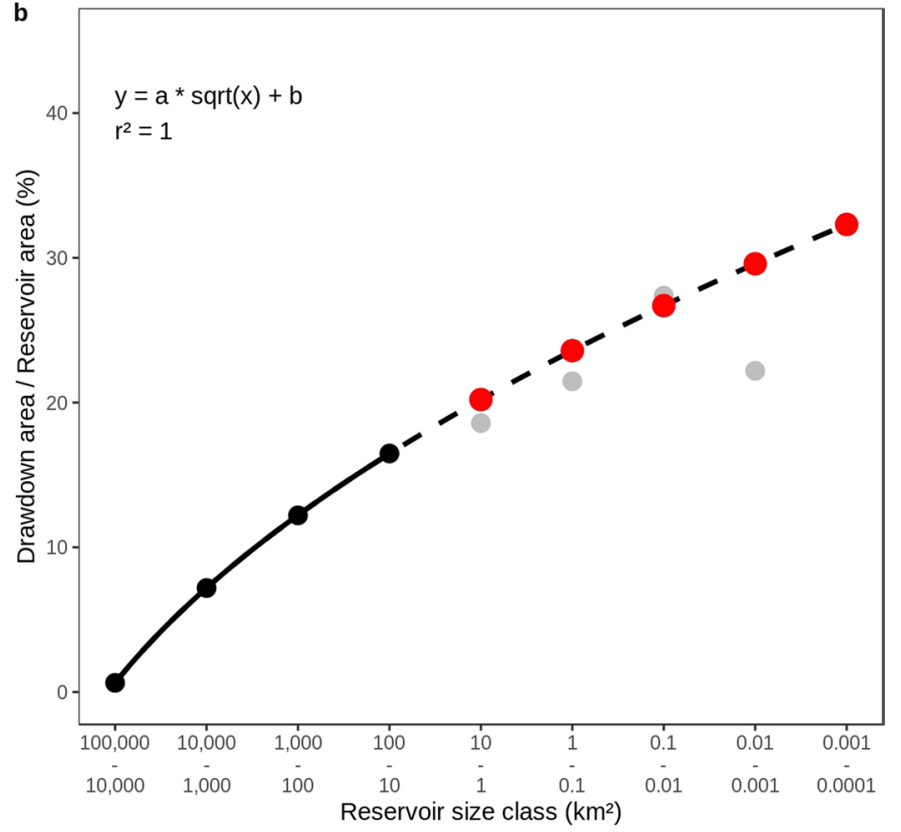

d

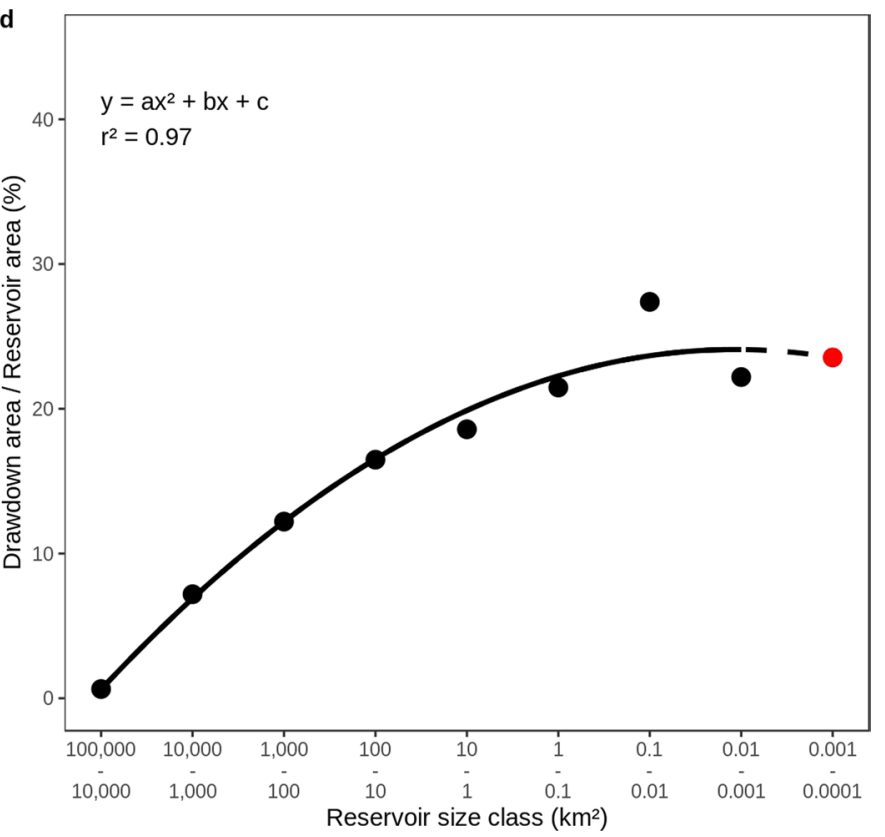

Extended Data Fig. 9 | Modelling of relationship between drawdown area and reservoir area. a linear model (LM), b Square root model (Sqrt), c Logarithmic model (Log), d Polynomial model (Poly). a-d Black and grey dots show ratios as observed in the GRSAD dataset. Black dots were used for model fitting, red dots show extrapolated values. Reservoirs larger $10 \mathrm{~km}^{2}$ were used to fit models a-c, as coverage of smaller reservoirs is considered to be increasingly incomplete in the underlying data set. In contrast, all available data was used for fitting the polynomial model (d) in order to achieve a hypothetical best fit. 


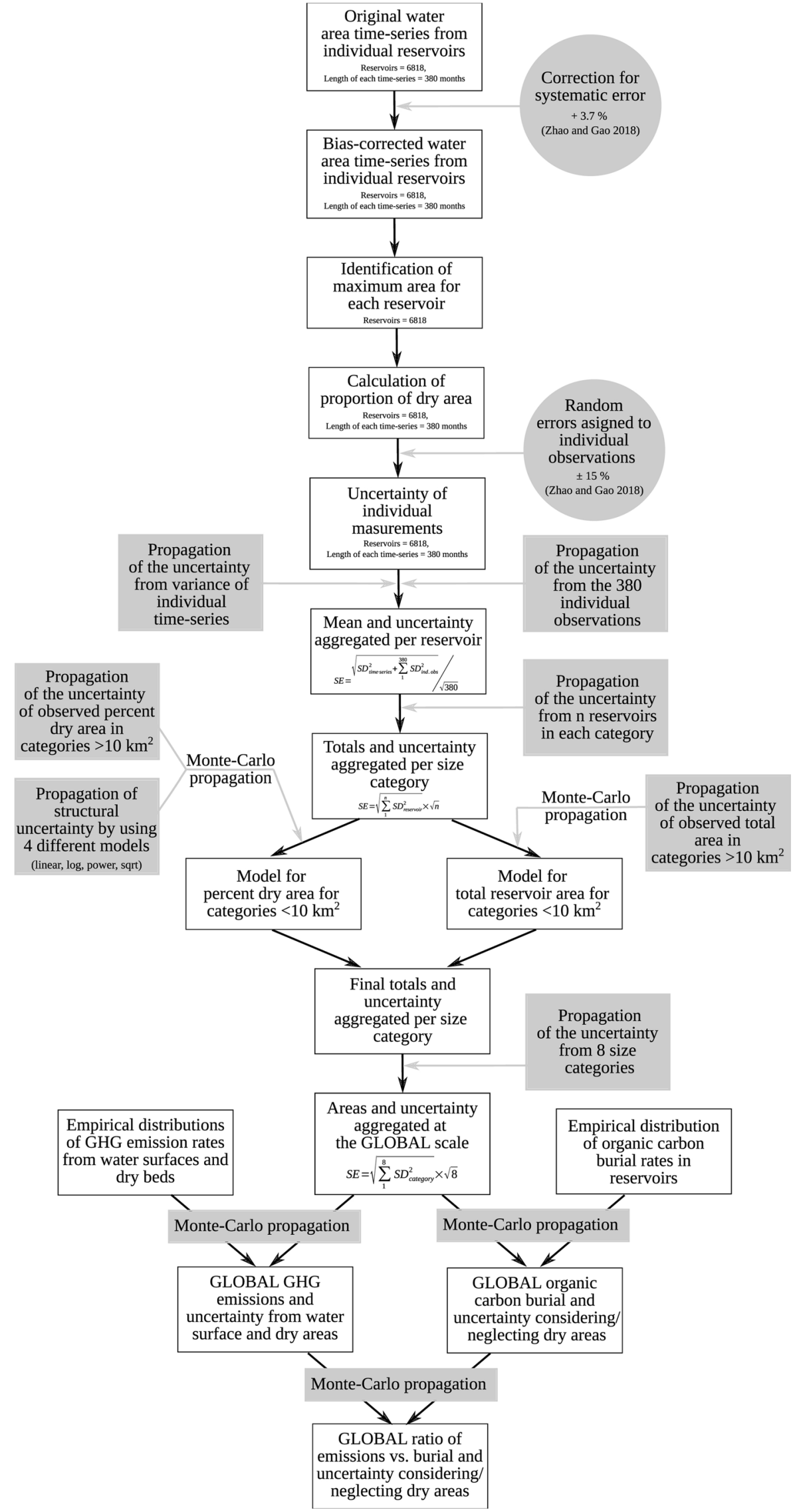

Extended Data Fig. 10 | Schematic workflow of analysis and uncertainty treatment performed in this study. Uncertainties from estimating both, global drawdown area and GHG emissions were propagated throughout the analysis. 